\title{
IMPACTO DE CÃES (Canis familiaris) E GATOS (Felis catus) ERRANTES SOBRE A FAUNA SILVESTRE EM AMBIENTE PERI- URBANO
}

\section{Cláudia Bueno de Campos}

Dissertação apresentada à Escola Superior de Agricultura "Luiz de Queiroz", Universidade de São Paulo, para obtenção do título de Mestre em Ecologia de Agroecossistemas.

P I R A C I C A B A

Estado de São Paulo - Brasil

Novembro - 2004 


\title{
IMPACTO DE CÃES (Canis familiaris) E GATOS (Felis catus) ERRANTES SOBRE A FAUNA SILVESTRE EM AMBIENTE PERI- URBANO
}

\author{
Cláudia Bueno de Campos \\ Bióloga
}

Orientador: Prof. Dr. LUCIANO MARTINS VERDADE

Dissertação apresentada à Escola Superior de Agricultura "Luiz de Queiroz",

Universidade de São Paulo, para obtenção do título de Mestre em Ecologia de Agroecossistemas.

P I R A C I C A B A

Estado de São Paulo - Brasil

Novembro - 2004 


\section{Dados Internacionais de Catalogação na Publicação (CIP) DIVISÃO DE BIBLIOTECA E DOCUMENTAÇÃO - ESALQ/USP}

\section{Campos, Cláudia Bueno de}

Impacto de cães (Canis familiaris) e gatos (Felis catus) errantes sobre a fauna silvestre em ambiente peri-urbano / Cláudia Bueno de Campos. - - Piracicaba, 2004.

55 p. : il.

Dissertação (Mestrado) - - Escola Superior de Agricultura Luiz de Queiroz, 2004.

Bibliografia.

1. Ambiente urbano 2. Biodiversidade 3. Cão 4. Ecologia animal 5. Educação ambiental 6. Fauna silvestre 7. Gato 8. Impacto ambiental 9. Mamíferos - Predação -I. Título

CDD 591.5 


\section{DEDICATÓRIA}

Dedico aos meus pais pelo grande Amor existente $e$ à minha família pela união de sempre. 


\section{AGRADECIMENTOS}

Agradeço ao meu orientador Prof.Dr. Luciano Martins Verdade pelos vários ensinamentos e auxílios;

Ao meu co-orientador Dr. Peter G. Crawshaw Jr. que, mesmo distante, estava sempre pronto para ajudar no que fosse necessário;

A Kátia agradeço de coração, pois desde o início nunca hesitou em ensinar o que sabe e muito menos em ajudar nos diversos momentos difíceis e principalmente pela amizade;

Ao Pedro pelas dicas profissionais, pelos diversos livros emprestados, pelos esqueletos e fezes que encontrou no campo doados, pelas viagens divertidas a campo e pela amizade;

Ao Anderson pela ajuda e amizade que proporcionaram vários momentos descontraídos, mesmo que alguns fossem difíceis;

A estagiária Carolina pela grande ajuda em campo durante as coletas, no laboratório durante a manipulação e triagem das fezes dos cães e gatos e, principalmente, por continuar me ajudando neste meio "cheiroso" do estudo da dieta de carnívoros;

Ao Cantarelli pelas informações sobre as burocracias desta vida e pela amizade;

Ao André pela amizade e as agradáveis modinhas de viola durante os churrascos;

Ao veterinário Luis Bassetti pelas diversas informações sobre cães e gatos domésticos; 
Aos estagiários Gabriel e Henrique pelo trabalho realizado com o mapa do Campus;

Ao Prof. Gilberto por ter acreditado em meu potencial e por permitir utilizar os equipamentos para as fotomicrografias dos pêlos;

A Graziela pelos artigos fornecidos e pelos pontos salvos no GPS;

A Carla pela ajuda e pelos diversos pêlos de pequenos mamíferos doados;

Aos estagiários Solange, Sarah e Fábio que, mesmo por um curto espaço de tempo, participaram deste trabalho;

A todos os companheiros do Laboratório de Ecologia Animal e ao funcionário Édson, que de uma forma ou de outra participaram de minha vida nestes anos de trabalho e estudo;

Aos Profs. Luigi Boitani e Paolo Ciucci e sua equipe por me aceitarem para um estágio em terras italianas no projeto sobre a biologia e conservação dos lobos, por fornecerem as diversas informações sobre a espécie enriquecendo assim meus discretos conhecimentos sobre estes maravilhosos animais;

Aos meus familiares que tanto ajudaram para que esta viagem fosse realizada;

A Vóva (assim a chamávamos) que até o último minuto de sua lucidez e vida expressou orgulho por me ver em terras italianas;

A Rebeca e Nina por me receberem sempre alegres com suas brincadeiras caninas e felinas, proporcionando muitos momentos de descontração;

Ao meu amor, companheiro e amigo Eduardo por compreender os vários dias sacrificados para a realização deste trabalho;

E a todos aqueles que, próximos ou distantes, participam de mais uma fase de minha vida... muito obrigado. 


\section{SUMÁRIO}

Página

LISTA DE FIGURAS ............................................................. viii

LISTA DE TABELAS ........................................................... $\quad \mathrm{x}$

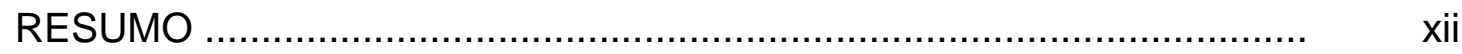

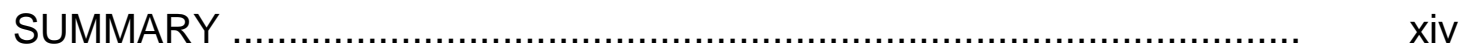

1 INTRODUÇÃO ................................................................. 1

2 REVISÃO DE LITERATURA ................................................. 5

3 MATERIAL E MÉTODOS ....................................................... 11

3.1 Área de Estudo ......................................................... 11

3.2 Método de Contagem dos Animais ........................................ 14

3.3 Qualificação e Quantificação das Dietas .................................... 15

3.4 Predação da Fauna Silvestre ................................................ 18

3.5 Metodologia Analítica ................................................................ 18

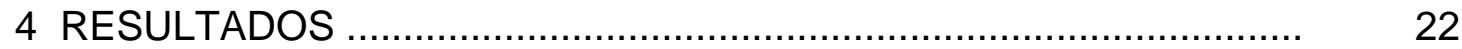

4.1 Distribuição e Abundância de Cães e Gatos Errantes ................... 22

4.2 Uso do Habitat ................................................................ 23

4.3 Qualificação e Quantificação da Dieta ...................................... 26

4.3.1 Análise da Dieta dos Cães Errantes ........................................ 31

4.3.2 Análise da Dieta dos Gatos Errantes ........................................ 32

4.3.3 Amplitude e Sobreposição do Nicho Alimentar ........................... 33

4.3.4 Biomassa Consumida Estimada ............................................. 33 
4.3.5 Estimativa da Pressão de Predação da Fauna Silvestre .............. 36

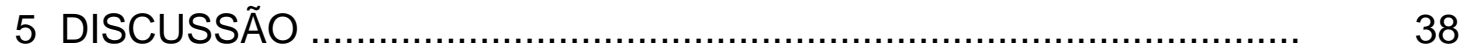

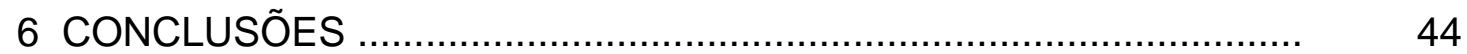

6.1 Considerações Finais ..................................................... 44

6.2 Conclusões .............................................................. 46

REFERÊNCIAS BIBLIOGRÁFICAS ......................................... 47 


\section{LISTA DE FIGURAS}

Página

1 Cães (Canis familiaris) e gatos (Felis catus) errantes em área periurbana do Campus "Luiz de Queiroz" da Universidade de São Paulo (Fotos: Cláudia B. Campos)

2 Localização do Campus "Luiz de Queiroz" da Universidade de São Paulo, Piracicaba, SP

3 Campus "Luiz de Queiroz" da Universidade de São Paulo, Piracicaba, SP, ambiente peri-urbano: área urbana, área suburbana e área rural (Fonte: Divisão de Infraestrutura / ESALQ / USP)

4 Campus "Luiz de Queiroz" da Universidade de São Paulo, Piracicaba, SP: transecto na área rural (rosa) e na área suburbana (verde) (adaptado de Gheler-Costa et al., 2002)

5 Fotomicrografias dos padrões microestruturais dos pêlos-guarda de mamíferos: Medula: a) Canis familiaris, c) Calomys spp., d) Felis catus, f) Galictis cuja e g) Olygoryzomys nigripes; Cutícula: b) Canis familiaris, e) Felis catus e h) Olygoryzomys nigripes

6 Localização dos cães (Canis familiairs) e gatos (Felis catus) durante o levantamento no mês de julho de 2002 no Campus "Luiz de Queiroz" da Universidade de São Paulo

7 Localização dos cães (Canis familiairs) e gatos (Felis catus) durante o levantamento no mês de janeiro de 2003 no Campus "Luiz de Queiroz" da Universidade de São Paulo 
8 Frequência relativa de ocorrência dos itens encontrados nas amostras de fezes de cães errantes coletadas no Campus "Luiz de Queiroz": a) inverno de 2002 ( $N=99)$ e b) verão de $2003(\mathrm{~N}=38)$....

9 Frequência relativa de ocorrência dos itens encontrados nas amostras de fezes de gatos errantes coletadas no Campus "Luiz de Queiroz": a) inverno de 2002 ( $N=48)$ e b) verão de $2003(\mathrm{~N}=49)$ 


\section{LISTA DE TABELAS}

Página

1 Mamíferos silvestres do Campus "Luiz de Queiroz" da Universidade de São Paulo em Piracicaba, SP, Brasil (Fonte: Gheler-Costa et al. 2002)

2 Principais zoonoses associadas a cães e gatos domésticos e/ou errantes

3 Número de cães e gatos errantes, baseado na identificação das características físicas das duas espécies, durante levantamento no inverno de 2002 e verão de 2003 no Campus "Luiz de Queiroz"

4 Número total de cães e gatos errantes avistados durante levantamento no inverno de 2002 e verão de 2003 nas áreas rural e suburbana do Campus "Luiz de Queiroz"

5 Itens encontrados em 234 amostras de fezes de cães e gatos errantes coletadas durante o inverno de 2002 e verão de 2003 no Campus "Luiz de Queiroz"

5 Itens encontrados em 234 amostras de fezes de cães e gatos errantes coletadas durante o inverno de 2002 e verão de 2003 no Campus "Luiz de Queiroz"

5 Itens encontrados em 234 amostras de fezes de cães e gatos errantes coletadas durante o inverno de 2002 e verão de 2003 no Campus "Luiz de Queiroz" 
5 Itens encontrados em 234 amostras de fezes de cães e gatos errantes coletadas durante o inverno de 2002 e verão de 2003 no Campus "Luiz de Queiroz"

6 Amplitude do nicho alimentar $(B)$ de cães e gatos errantes do Campus "Luiz de Queiroz"

7 Sobreposição do nicho alimentar $(O)$ de cães e gatos errantes do Campus "Luiz de Queiroz"

8 Biomassa consumida estimada das espécies de mamíferos identificadas em 137 amostras de fezes de cães errantes coletadas no Campus "Luiz de Queiroz"

9 Biomassa consumida estimada das espécies de mamíferos identificadas em 97 amostras de fezes de gatos errantes coletadas no Campus "Luiz de Queiroz"

10 Pressão estimada de predação por cães e gatos sobre os mamíferos no Campus "Luiz de Queiroz" 


\title{
IMPACTO DE CÃES (Canis familiaris) E GATOS (Felis catus) ERRANTES SOBRE A FAUNA SILVESTRE EM AMBIENTE PERI- URBANO
}

\author{
Autora: CLÁUDIA BUENO DE CAMPOS \\ Orientador: Prof. Dr. LUCIANO MARTINS VERDADE
}

\section{RESUMO}

Os objetivos deste estudo foram quantificar a população de cães (Canis familiaris) e gatos (Felis catus) errantes em ambiente peri-urbano representado pelo Campus "Luiz de Queiroz" da Universidade de São Paulo, em Piracicaba, SP; descrever e comparar qualitativa e quantitativamente a dieta das duas espécies e estimar sua pressão de predação sobre as espécies silvestres de mamíferos. Durante os meses de julho de 2002 e janeiro de 2003, foram realizadas observações visuais e coletadas amostras de fezes de cães e gatos ao longo de uma transeção linear. Foram amostrados $0,276 \mathrm{~km}^{2}$, ou $3,2 \%$ da área de 860ha do Campus. As características físicas de cada indivíduo (espécie, raça, pelagem, sexo, tamanho e marcas naturais) foram registradas para o cálculo da abundância das duas espécies na área amostrada, assim como o número de encontros por dia e por ambientes (rural e suburbano). A dieta foi analisada através das amostras de fezes que foram esterilizadas, lavadas, secas e triadas, sendo seus componentes identificados com o auxílio de referências bibliográficas. A importância de cada item foi expressa como 
porcentagem do número total de itens encontrados e como porcentagem de uma estimativa da biomassa consumida. A amplitude e sobreposição de nicho foram calculadas através dos índices de Levins e Pianka, respectivamente. $\mathrm{O}$ resultado da estimativa de abundância dos cães e gatos domésticos na área amostrada foi de 42 cães e 81 gatos. Cães e gatos são mais abundantes em ambiente suburbano que rural $(T=3,78, p<0,001, N=55 ; T=8,38, p<0,001$, $\mathrm{N}=55$ respectivamente) e os gatos são mais abundantes que cães em ambiente suburbano ( $T=6,76, p<0,001, N=55)$, porém não houve diferença significativa quanto à abundância de cães e gatos em ambiente rural $(T=0,82$, $p=0,46, N=55$ ). Os resultados das análises das dietas indicam que os cães e gatos domésticos errantes são oportunistas de hábito generalista. Em 234 amostras de fezes foram detectadas 1212 ocorrências de 57 itens (68,4\% de origem animal, $15,8 \%$ de origem vegetal e $15,8 \%$ formados por itens não alimentares). Considerando os itens de origem animal da dieta das duas espécies, invertebrados foram os mais consumidos, seguidos por mamíferos (cães: 57,05\% e 25,15\%; gatos: 63,24\% e 20,51\%, respectivamente). A amplitude de nicho $(B)$ foi de 0,4463 para cães e 0,4892 para gatos. A sobreposição de nicho $(O)$ foi próxima de completa $(0,97108)$. $O$ consumo de mamíferos por cães foi estimado entre 16,76 e 25,42 kg/ind/ano e por os gatos foi entre 2,01 e 2,9 kg/ind/ano, o que pode ser a causa das baixas densidades populacionais de pequenos mamíferos silvestres na área de estudo. 


\title{
IMPACT OF FREE-RANGING DOGS (Canis familiaris) AND CATS (Felis catus) ON WILDLIFE IN A SUBURBAN AREA
}

\author{
Author: CLÁUDIA BUENO DE CAMPOS \\ Advisor: Prof. Dr. LUCIANO MARTINS VERDADE
}

\section{SUMMARY}

The goals of this study were to quantify the population of free-ranging dogs (Canis familiaris) and cats (Felis catus) in suburban areas; to describe and compare the diet of both species, and to estimate their predation pressure on the wildlife, at Campus " Luiz of Queiroz " of the University of São Paulo, in Piracicaba, SP. During the months of July 2002 and January 2003, visual observations and scats collection of dogs and cats were accomplished along a transect line. The sampled area comprised $0.276 \mathrm{~km}^{2}$, or $3.2 \%$ of the $860 \mathrm{ha}$ of the Campus area. Physical characteristics of each individual (species, race, fur, sex, size and natural marks) were registered for the calculation of the abundance of both species in the sampled area, as well as the number of encounters a day and the environment (rural and suburban). The diet was analyzed through scats sterilized, washed, dried and sorted. Their components were identified with the aid of bibliographical references. The importance of each item was expressed as the percentage of the total number of items found and as the percentage of an estimate of the consumed biomass. Breadth and overlap 
niche were calculated through the indexes of Levins and Pianka, respectively. The results of estimate abundance of free-ranging dogs and cats in the sampled area were of 42 and 81 respectively. Dogs and cats are more abundant in suburban than rural environment $(T=3.78, p<0.001, N=55 ; T=8.38, p$ $<0.001, N=55$ respectively) and the cats are more abundant than dogs in suburban environment $(T=6.76, p<0.001, N=55)$, even though there was no significant difference between the abundance of dogs and cats in rural environment $(T=0.82, p=0.46, N=55)$. The results of diet analyses indicated that free-ranging dogs and cats are opportunistic predators of generalist habit. In 234 samples of scats 1212 occurrences of 57 items (68.4\% of animal origin, $15.8 \%$ of vegetable origin and $15.8 \%$ formed by no food items) were detected. Considering the items of animal origin found in the diet of both species, invertebrates were the most consumed, followed by mammals (dogs: $57.05 \%$ and $25.15 \%$; cats: $63.24 \%$ and $20.51 \%$, respectively). Niche breadth $(B)$ was 0.4463 for dogs and 0.4892 for cats. Niche overlap $(O)$ was almost complete (0.97108). The consumption of mammals was estimated between 16.76 and $25.42 \mathrm{~kg} / \mathrm{ind} / \mathrm{year}$ for dogs and between 2.01 and $2.9 \mathrm{~kg} / \mathrm{ind} / \mathrm{year}$ for cats. This is a possible reason for the low population densities of small wild mammals in the study area. 


\section{INTRODUÇÃO}

Cães (Canis familiaris) e gatos (Felis catus) domésticos são velhos companheiros da história humana, sendo encontrados em quase todos os lugares do mundo (Boitani, 1995; Clutton-Brock, 1995; Serpell, 2000). No entanto, esta grande distribuição pode gerar problemas, tais como predação de animais domésticos e silvestres, transmissão de doenças, além de ataques a seres humanos, o que demanda crescente atenção por parte de gestores e cientistas.

Apesar da ampla distribuição e da estreita relação com o homem, são poucos os estudos realizados com estas espécies em estado errante (Lowry \& McArthur, 1978; Serpell, 1995). Informações sobre a biologia e ecologia de cães e gatos errantes, bem como a sua interação com a fauna silvestre, são importantes para direcionar ações adequadas de manejo, garantindo melhor convivência entre o homem, os animais domésticos e a fauna silvestre. $O$ crescente abandono e descuido de cães e gatos domésticos na maioria das cidades brasileiras, vem causando preocupação para as autoridades responsáveis pela saúde pública, pelo fato de que apenas uma parte desses animais é vacinada ou está sob controle de um responsável (Coelho et al., 2001).

O Campus mantém criações de animais domésticos de valor econômico e científico e uma considerada diversidade de mamíferos (Tabela 1). 
Tabela 1. Mamíferos silvestres do Campus "Luiz de Queiroz" da Universidade de São Paulo em Piracicaba, SP, Brasil (Fonte: Gheler-Costa et al. 2002)

\begin{tabular}{|c|c|c|}
\hline Classificação & Autor & Nome comum \\
\hline \multicolumn{3}{|l|}{ Ordem Artiodactyla } \\
\hline \multicolumn{3}{|l|}{ Família Cervidae } \\
\hline \multicolumn{3}{|l|}{ Subfamília Capreolinae } \\
\hline Mazama gouazoubira & G. Fischer, 1814 & veado-catingueiro \\
\hline \multicolumn{3}{|l|}{ Ordem Carnívora } \\
\hline \multicolumn{3}{|l|}{ Família Canidae } \\
\hline $\begin{array}{l}\text { Cerdocyon thous } \\
\text { Família Procyonidae }\end{array}$ & Linnaeus, 1766 & cachorro-do-mato \\
\hline $\begin{array}{l}\text { Nasua nasua } \\
\text { Ordem Didelphimorphia } \\
\text { Família Didelphidae }\end{array}$ & Linnaeus, 1766 & coati \\
\hline $\begin{array}{l}\text { Didelphis albiventris } \\
\text { Lutreolina crassicaudata } \\
\text { Ordem Lagomorpha } \\
\text { Família Leporidae }\end{array}$ & $\begin{array}{c}\text { Lund, } 1840 \\
\text { Desmarest, } 1804\end{array}$ & $\begin{array}{l}\text { gambá-de-orelha-branca } \\
\text { cuíca-de-cauda-grossa }\end{array}$ \\
\hline $\begin{array}{r}\text { Lepus spp. } \\
\text { Sylvilagus brasiliensis }\end{array}$ & $\begin{array}{l}\text { Linnaeus, } 1758 \\
\text { (Linnaeus, } 1758\end{array}$ & $\begin{array}{l}\text { lebre-européia } \\
\text { tapiti }\end{array}$ \\
\hline \multicolumn{3}{|l|}{ Ordem Primates } \\
\hline \multicolumn{3}{|l|}{ Família Callitrichidae } \\
\hline \multicolumn{2}{|l|}{ Ordem Rodentia } & sagui-de-tufo-branco \\
\hline \multicolumn{3}{|l|}{ Subordem Sciurognathi } \\
\hline \multicolumn{3}{|l|}{ Família Muridae } \\
\hline \multicolumn{3}{|l|}{ Subfamília Sigmodontinae } \\
\hline Oligoryzomys nigripes & Olfers, 1818 & rato \\
\hline Calomys tener & Winge, 1887 & rato \\
\hline Subfamília Murinae & & \\
\hline $\begin{array}{l}\text { Rattus Rattus } \\
\text { Família Erethizontidae }\end{array}$ & Linnaeus, 1758 & rato-doméstico \\
\hline $\begin{array}{l}\text { Coendou prehensilis } \\
\text { Família Caviidae }\end{array}$ & Linnaeus, 1758 & ouriço-cacheiro \\
\hline $\begin{array}{l}\text { Cavia aperea } \\
\text { Família Hydrochaeridae }\end{array}$ & Erxleben, 1777 & preá \\
\hline $\begin{array}{l}\text { Hydrochoerus hydrochaeris } \\
\text { Família Myocastoridae }\end{array}$ & Linnaeus, 1766 & capivara \\
\hline $\begin{array}{l}\text { Myocastor coypus } \\
\text { Ordem Xenartha }\end{array}$ & Molina, 1782 & ratão-do-banhado \\
\hline Família Dasypodidae & & \\
\hline Dasypus novemcinctus & Linnaeus, 1758 & tatu-galinha \\
\hline
\end{tabular}


O Campus "Luiz de Queiroz" foi selecionado para este estudo por abrigar cães e gatos em situação semelhante às encontradas em outras regiões do país. No Campus, podemos observar a presença de vários cães e gatos errantes (Figura 1), que ingressam livremente na área ou que são abandonados por populares. Sua pressão de predação sobre a fauna silvestre é ainda desconhecida. No entanto, Gheler-Costa et al., (2002) encontraram baixas densidades populacionais de mamíferos silvestres no Campus, possivelmente associadas à sua grande população de cães e gatos errantes. Neste contexto, o presente estudo tem os seguintes objetivos:

a. Levantamento das populações de cães e gatos errantes no Campus "Luiz de Queiroz", da Universidade de São Paulo;

b. Descrição qualitativa e quantitativa de sua dieta; e

c. Estimativa de sua pressão de predação sobre as espécies de mamíferos silvestres local. 

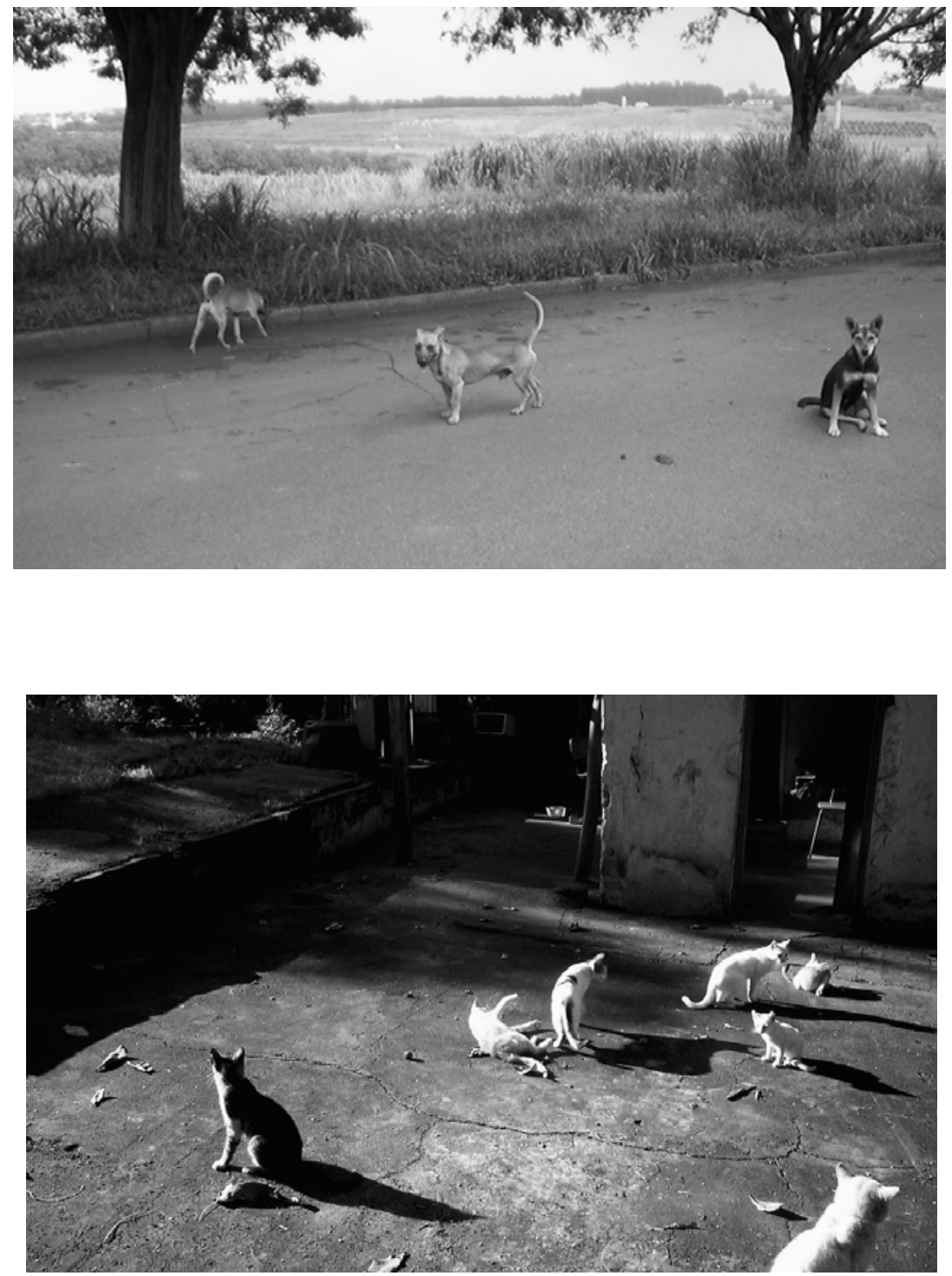

Figura 1 - Cães (Canis familiaris) e gatos (Felis catus) errantes em área periurbana do Campus "Luiz de Queiroz" da Universidade de São Paulo (Fotos: Cláudia B. Campos) 


\section{REVISÃO DE LITERATURA}

A domesticação animal, comumente considerada uma inovação humana, pode também ser descrita como um processo evolucionário. Há aproximadamente 12.000 anos, os humanos começaram a experimentar uma profunda mudança em seus estilos de vida quando começaram a recrutar animais e cultivar plantas para uso próprio. Este novo hábito causou rápidas mudanças evolucionárias e, em pouco tempo, diferentes animais domésticos e plantas apareceram em muitas partes do mundo (Morey, 1994).

Evidências arqueológicas indicam que o cão foi a primeira espécie animal a ser domesticada. Isto ocorreu no final da última Era do Gelo, quando toda a subsistência humana ainda dependia da caça, procura e coleta de alimentos. A descoberta mais recente de um cão domesticado consiste de uma mandíbula encontrada numa sepultura Paleolítica em Oberkassel, Alemanha. O fóssil de cão mais antigo encontrado até hoje foi datado de 14.000 anos atrás (Clutton-Brock, 1984 e 1995). Na América do Sul, foram encontrados ossos de cães domésticos em cavernas do Chile que datam de 8.500 a 6.500 antes do presente (Clutton-Brock, 1988).

A exata origem da domesticação dos gatos ainda é desconhecida, mas existem razões para pensar que o processo ocorreu durante o início da civilização humana no Crescente Fértil do Oriente Médio. O motivo da domesticação pode ter sido o combate ao grande número de ratos que devastavam os alimentos armazenados (Robinson, 1984). Os egípcios associavam animais específicos com deuses e, por isso, os gatos eram 
mantidos em templos como símbolos religiosos já em cerca de 4.500 a.C. (Robinson, 1984; Serpell, 2000).

A família Canidae é um grupo de carnívoros dividido em 38 espécies, incluindo o cão doméstico (Clutton-Brock, 1995), sendo seis espécies selvagens encontradas no Brasil (Pitman et al., 2002). O cão (C. familiaris) é o único da família que pode ser considerado totalmente domesticado. No entanto, a raposa vermelha (Vulpes vulpes) e o mão-pelada (Nyctereutes procyonoides) são criados em cativeiro por causa da pele (Bradshaw \& Nott, 1995).

A opinião das pessoas sobre cães domésticos tem uma tendência de abranger extremos. Para um crescente setor da população, o cão é visto como um animal sujo e perigoso, com poucas qualidades, uma fonte de vícios, ataques a crianças, riscos de doenças debilitantes ou fatais e produtor de inaceitáveis níveis de poluição orgânica nas ruas e parques. Por outro lado, existe um grande grupo de amantes de cães, para quem este animal é fiel e a quem se tem um incondicionável amor. Para estas pessoas, a idéia de banir um cão ou restringir seu acesso às áreas públicas, é como banir uma criança ou proibir que jovens brinquem nessas áreas (Serpell, 1995).

Um dos fatores que pode aumentar a não aprovação humana em relação aos cães domésticos é a mudança de seu comportamento quando passam a frequentar constantemente as ruas ou são abandonados por seus donos (Beck, 1975). Segundo Nesbitt (1975), um cão de estimação que sai às ruas livremente pode tornar-se errante ou mesmo, casualmente, um cão feral.

A distinção entre os termos feral e errante é, às vezes, um problema de titulação ou grau. Para Boitani et al. (1995), um cão feral é considerado selvagem, pois ele consegue sobreviver sem nenhum contato com humanos. Além disto, normalmente, cães ferais não permitem a aproximação e podem ser considerados perigosos. O cão errante mantém um vínculo social com os humanos, associando-se mesmo que temporariamente à figura de um "dono". No entanto, a distinção entre doméstico, errante e feral é difícil de ser feita 
apenas pela observação de seu comportamento (Green \& Gipson, 1994; Nesbitt, 1975; Scott \& Causey, 1973).

Um cão feral é melhor descrito como oportunista, pois muitos sobrevivem comendo animais atropelados, aves aquáticas debilitadas, animais jovens, vegetais, frutas e, ocasionalmente, lixo. Ele pode ser um eficiente predador de pequenos e médios animais (Green \& Gipson, 1994; Nesbitt, 1975) e eventualmente matar animais domésticos como, por exemplo, bezerros, caçando em bando (Scott \& Causey, 1973).

A recente atenção dada aos ataques de cães às pessoas ou riscos de doenças talvez seja desproporcional a seus riscos reais, mas reflete uma antipatia ao cão que não deve ser subestimada. Recentemente, esse sentimento tem resultado em um aumento de restrições às atividades dos cães e de seus donos, incluindo banimento legal de determinadas raças ou mesmo a execução de qualquer indivíduo de uma determinada raça cujo dono tenha permitido sua presença sem focinheira em lugar público (Serpell, 1995).

A família Felidae é constituída por 37 espécies selvagens, sendo oito encontradas no Brasil (Oliveira, 1994; Oliveira e Cassaro, 1999; Pitman et al., 2002). O gato doméstico (F. catus) está distribuído pelo mundo todo (Coleman et al., 1997) e é encontrado numa relação comensal onde quer que as pessoas se encontrem, podendo ter uma população igual à população humana em algumas áreas urbanas e suburbanas (Fitzwater, 1994).

Os gatos são adaptáveis e suscetíveis a adaptações em seu comportamento, respondendo sensivelmente às mudanças do meio. Além disso, eles são altamente variáveis em seu habitat. Alguns gatos passam muito tempo caçando, enquanto outros raramente deixam as residências de seus donos (Martin \& Bateson, 1988).

Os membros dessa família são caçadores solitários e obrigatoriamente carnívoros e preferem consumir carne fresca. Esses animais são relativamente fáceis de domesticar, mas apesar disso, eles são bem 
sucedidos no estado feral, isto é, vivendo sem provisões fornecidas pelo homem (Bradshaw et al., 1996).

Errantes ou ferais, os gatos são abundantes e caçadores bastante difundidos. Eles muitas vezes existem em maior densidade do que predadores nativos. Eles predam grande quantidade de animais silvestres, alguns raros ou ameaçados. Em algumas áreas suburbanas e meios rurais, os gatos domésticos em estado feral podem ser os mais abundantes predadores (Fitzwater, 1994).

Além de competir com predadores nativos também abrigam uma variedade de doenças (Coleman et al., 1997). Para ter e cuidar dos animais de estimação e ainda proteger os animais silvestres, é necessário um esforço para entender os efeitos desfavoráveis que os gatos errantes e ferais podem ter sobre os animais silvestres (Coleman et al., 1997).

Conforme informações do Centro de Controle de Zoonoses de São Paulo, no Brasil existem cerca de 25 milhões de cães e 11 milhões de gatos de estimação. Na cidade de São Paulo, estima-se a existência de 1,5 milhão de cães, em média um cão para cada sete habitantes, sendo $70 \%$ semidomiciliados, $20 \%$ domiciliados e $10 \%$ em total abandono. A vida livre de cães e gatos e o uso de lugares em comum por seres humanos e outros animais, facilitam a transmissão de diversas doenças através de seus dejetos e saliva, além do risco de mordeduras e arranhaduras (Lockwood, 1995). As principais zoonoses a eles associadas são apresentadas na Tabela 2. 
Tabela 2. Principais zoonoses associadas a cães e gatos domésticos e/ou errantes

\begin{tabular}{|c|c|c|}
\hline Zoonose & Descrição & Fonte \\
\hline Toxoplasmose & $\begin{array}{l}\text { Seu agente causal é um protozoário hospedado } \\
\text { por gatos, o Toxocara gondii. A transmissão pode } \\
\text { ocorrer através da inalação de oocistos, pela } \\
\text { ingestão acidental dos mesmos através de mãos, } \\
\text { alimentos ou água contaminados por fezes de } \\
\text { gato. }\end{array}$ & Frenkel, 1997 \\
\hline Cinomose & $\begin{array}{l}\text { Causada por um vírus (Morbilivirus spp.) } \\
\text { infectando cães por contato direto ou pelas vias } \\
\text { respiratórias. O homem pode transportar o vírus } \\
\text { em suas roupas de um local com um animal } \\
\text { infectado para outro, infectando outros animais. } \\
\text { No entanto, esta doença não é transmitida aos } \\
\text { seres humanos. }\end{array}$ & $\begin{array}{l}\text { Correa \& } \\
\text { Correa, } 1992\end{array}$ \\
\hline Leptospirose & $\begin{array}{l}\text { Causada por uma bactéria (Leptospira } \\
\text { interrogans) e afeta a maior parte dos animais. É } \\
\text { transmitida principalmente pela urina de ratos } \\
\text { contaminando a água, alimentos e outros animais } \\
\text { como cães, bovinos e animais silvestres. O } \\
\text { homem pode ser contaminado através da pele } \\
\text { lesada ou ingestão. }\end{array}$ & $\begin{array}{l}\text { Mascolli et al., } \\
2002\end{array}$ \\
\hline Raiva & $\begin{array}{l}\text { A raiva é uma das principais e mais conhecidas } \\
\text { zoonoses por suas consequências sérias e } \\
\text { caráter incurável. É transmitida pelo contato com } \\
\text { o animal contaminado pelo vírus Rhabdovirus, } \\
\text { que atinge de maneira letal o sistema nervoso do } \\
\text { indivíduo. }\end{array}$ & Beck, 1975 \\
\hline $\begin{array}{l}\text { Larva migrans } \\
\text { cutânea (bicho } \\
\text { geográfico) }\end{array}$ & $\begin{array}{l}\text { Os ovos eliminados junto com as fezes de cães e } \\
\text { gatos infectados por Ancylostoma spp. e } \\
\text { Uncinaria spp., liberam larvas capazes de } \\
\text { penetrar ativamente a pele podendo causar } \\
\text { lesões elevadas. }\end{array}$ & $\begin{array}{l}\text { Correa \& } \\
\text { Correa, } 1992\end{array}$ \\
\hline $\begin{array}{l}\text { Larva migrans } \\
\text { visceral ou ocular } \\
\text { (LMV) }\end{array}$ & $\begin{array}{l}\text { A transmissão se dá pela ingestão de terra, } \\
\text { vegetais ou água contaminados pelas fezes de } \\
\text { cães e gatos infectados por Toxocara canis ou } T \text {. } \\
\text { cati. Os ovos ingeridos liberam larvas nos } \\
\text { intestinos que penetram a mucosa ganhando } \\
\text { acirculação e migram pelos tecidos, podendo } \\
\text { formar cistos se alcançar a forma adulta. A } \\
\text { localização destes cistos nos olhos pode causar } \\
\text { cegueira. }\end{array}$ & $\begin{array}{l}\text { Correa \& } \\
\text { Correa, } 1992\end{array}$ \\
\hline
\end{tabular}


Segundo o Departamento de Zoonoses da Prefeitura de Piracicaba, estima-se que na cidade existam atualmente 40.000 cães e gatos domésticos, sendo 15.000 errantes. Mensalmente, o canil/gatil da cidade atende em média 120 chamadas da população para castração de animais, desinfestações de carrapatos, recolhimento de animais atropelados e captura de animais agressivos. Desde a inauguração do canil/gatil em maio de 2001, foram realizadas 900 eutanásias em animais que apresentavam riscos à saúde pública ou não tinham mais condições de sobrevivência (Américo ${ }^{1}$ ).

Pequenos e médios mamíferos e algumas aves podem fazer parte da dieta de cães e gatos domésticos (Errington, 1936; Jackson, 1951; Scott \& Causey, 1973; Coleman \& Temple, 1989; Bradshaw et al., 1996). Segundo Gheler-Costa et al. (2002), no Campus "Luiz de Queiroz" os pequenos mamíferos apresentam baixa densidade nas áreas agrícolas com intensa alteração do uso do solo, possivelmente associadas à pressão de predação por cães e gatos errantes.

Os hábitos alimentares de uma espécie influenciam, direta ou indiretamente, sua reprodução, comportamento social, territorialidade, distribuição geográfica, densidade populacional entre outros fatores. Uma das formas de obtenção de dados relativos à dieta de uma espécie é a coleta de amostras fecais para a análise dos itens nela existentes (Crawshaw, 1997). A análise do conteúdo fecal tem se tornado fundamental para pesquisas com carnívoros (Reynolds \& Aebischer, 1991), porém, pesquisas sobre hábitos alimentares de cães e gatos errantes e/ou ferais no Brasil ainda são praticamente inexistentes.

\footnotetext{
${ }^{1}$ AMÉRICO, L.. Comunicação pessoal, 2002.
} 


\section{MATERIAL E MÉTODOS}

\section{1 Área de Estudo}

A Escola Superior de Agricultura "Luiz de Queiroz", Universidade de São Paulo localiza-se no município de Piracicaba, região central do Estado de São Paulo, estando seu marco central localizado à latitude $22^{\circ} 42^{\prime} 30^{\prime \prime}$ Sul e longitude 47038'30" Oeste, com altitude média aproximada de $547 \mathrm{~m}$ (Barbin, 1999) (Figura 2). Conforme o sistema Köppen, o clima da região de Piracicaba é do tipo Cwa (temperatura quente com estiagem no inverno, sendo a temperatura no mês mais quente superior a $22^{\circ} \mathrm{C}$ e no mês mais frio inferior a $18^{\circ} \mathrm{C}$ ), com pluviosidade média anual de aproximadamente $1.200 \mathrm{~mm}$, distribuídas durante o ano (Setzer, 1946).

O Campus tem área total de 860 ha, formando um mosaico de vegetação com 196 ha de culturas anuais, 71 ha de culturas semi-perenes, 30 ha de culturas perenes, 109 ha de pastagens, 35 ha de reflorestamento e 67 ha de remanescentes florestais, correspondendo a cerca de 7,4\% da área total do Campus (Sparovek, 1993). A classe de solo predominante é TR (terra roxa estruturada), que ocupa cerca de $55 \%$ da superfície do Campus. Trata-se de solo com elevada fertilidade, mas com pouca representatividade no Estado de São Paulo (Sparovek, 1993). A vegetação original da região de Piracicaba é classificada como Floresta Estacional Semidecidual (Floresta Tropical Subcaducifólia) (IBGE, 1992). O conceito ecológico deste tipo de vegetação está condicionado pela estacionalidade climática: uma estação com épocas de intensas chuvas de verão seguida por estiagens acentuadas e outra subtropical 
sem período seco, mas com seca fisiológica provocada pelo frio do inverno (Veloso et al., 1991).

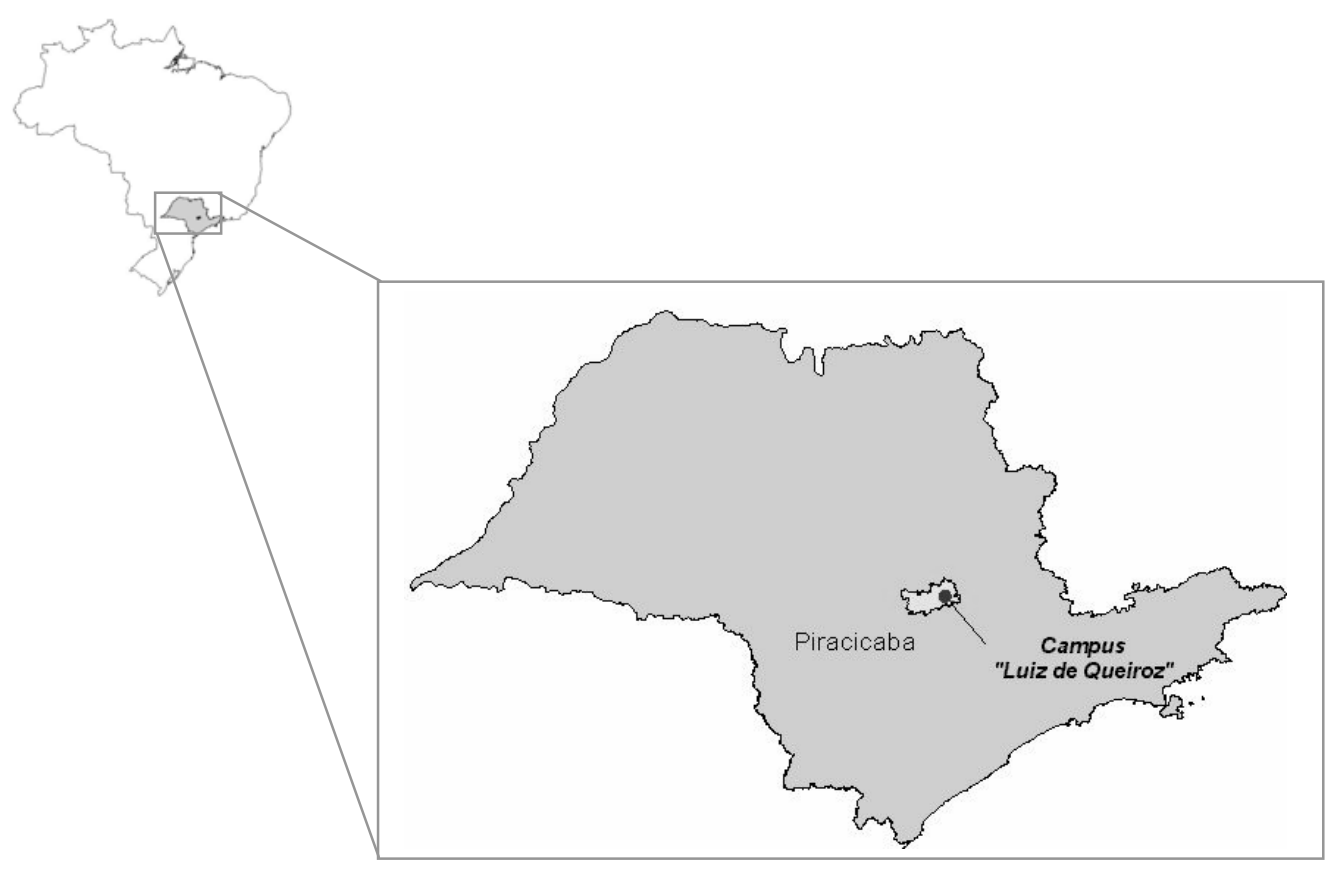

Figura 2 - Localização do Campus "Luiz de Queiroz" da Universidade de São Paulo, Piracicaba, SP

Devido a localização periférica do Campus em relação ao centro urbano de Piracicaba, para este estudo denominamos a área de peri-urbana (Figura 3). No interior do Campus pudemos distinguir duas áreas que foram amostradas e comparadas quanto à ocorrência de cães e gatos. As áreas de estudo foram divididas em ambiente rural, onde predominam culturas agrícolas com estradas não asfaltadas, e ambiente suburbano, em que predominam edifícios conectados por ruas asfaltadas e separados por parques e jardins (Figura 3). 


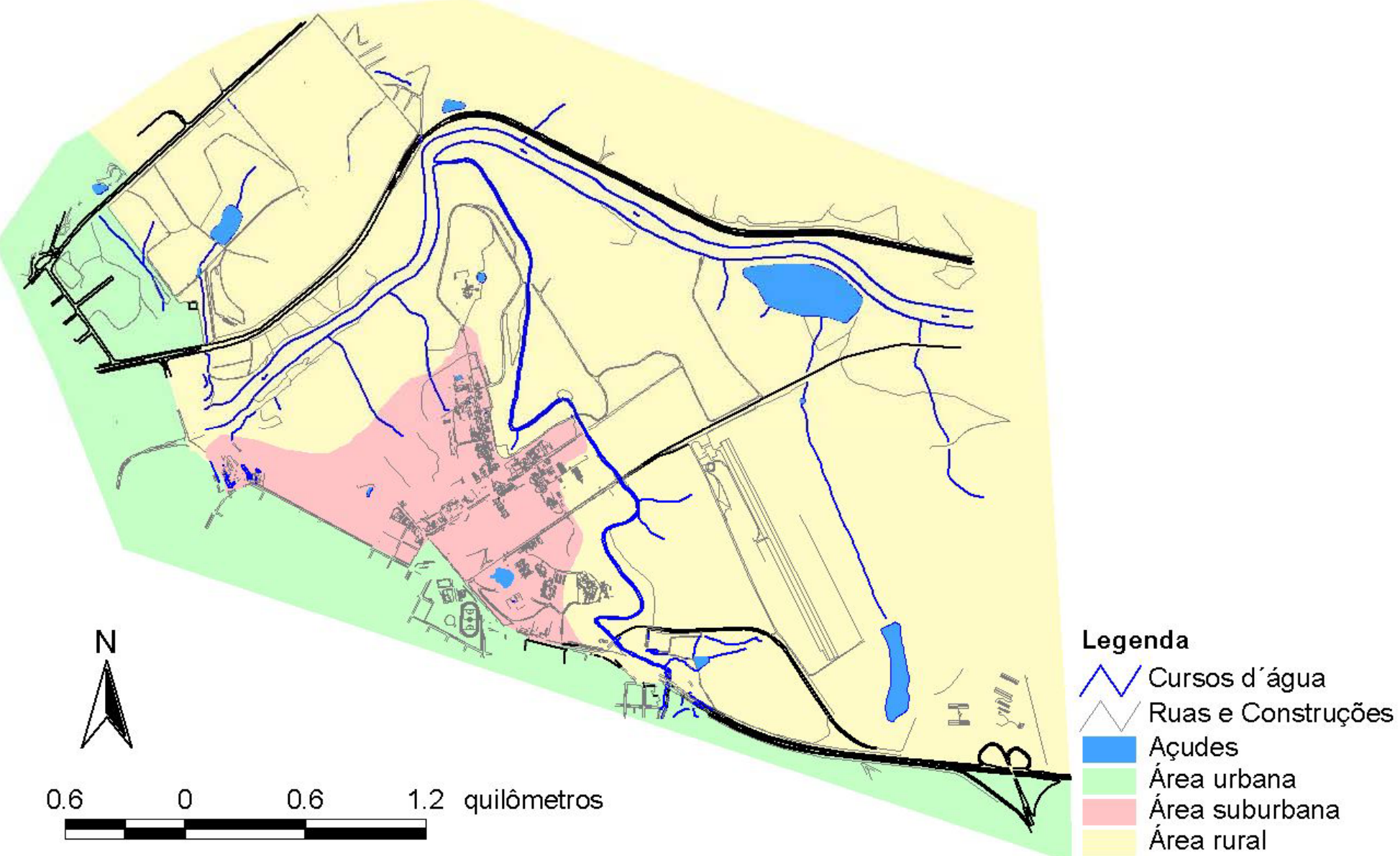

Figura 3 - Campus "Luiz de Queiroz" da Universidade de São Paulo, Piracicaba, SP, ambiente peri-urbano: área urbana, área suburbana e área rural (Fonte: Divisão de Infraestrutura / ESALQ/USP) 


\subsection{Método de Contagem dos Animais}

Durante o mês de maio de 2002 foram realizadas visitas na área de estudo para o levantamento prévio de campo a fim de reconhecer os ambientes que compõem o Campus e definição das transeções (Figura 4). Entre 01 a 31 de julho de 2002 (estação seca) e 01 a 31 de janeiro de 2003 (estação chuvosa) foram coletadas diariamente informações sobre a abundância e dieta de cães e gatos na área de estudo, totalizando respectivamente 26 e 29 dias.

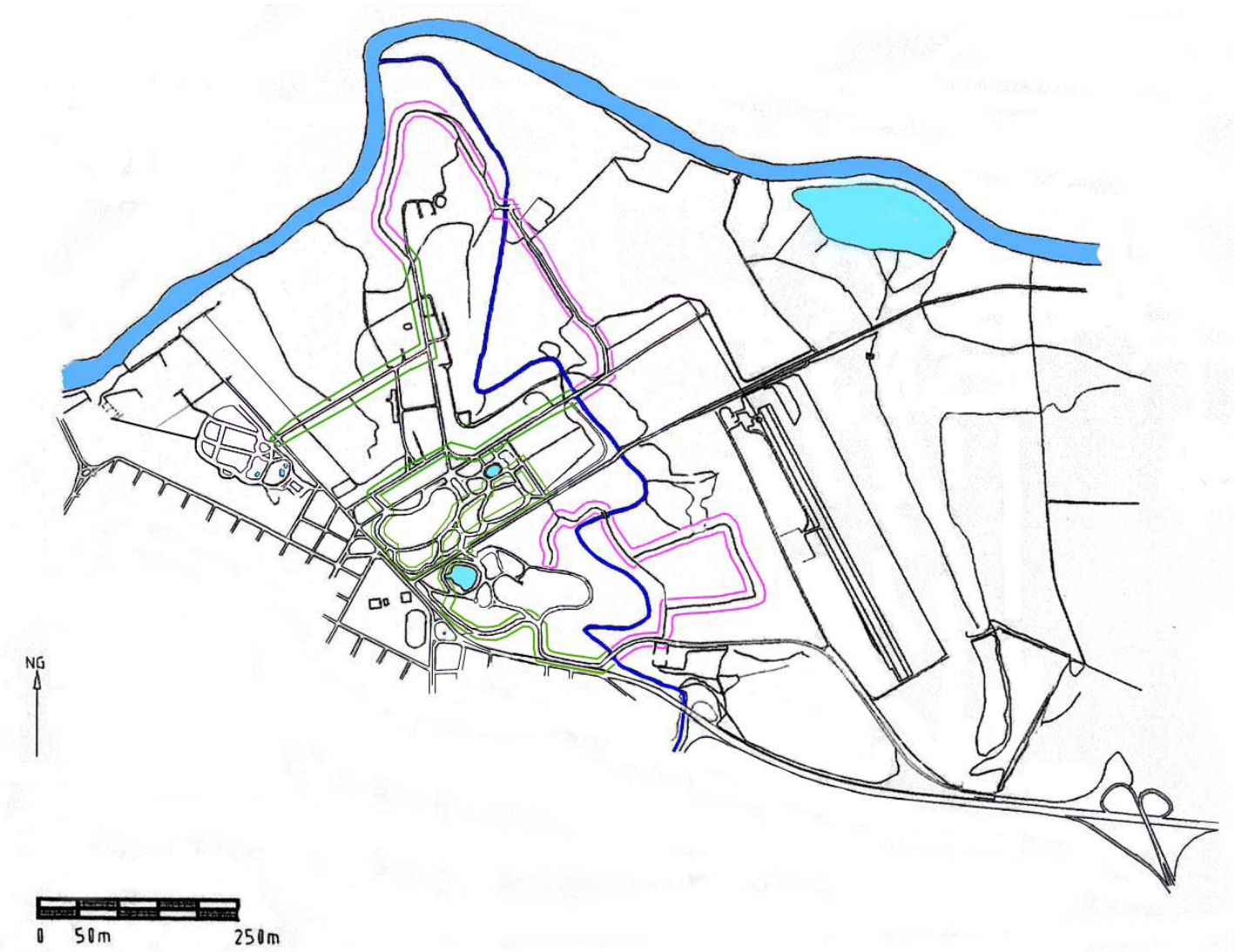

Figura 4 - Campus "Luiz de Queiroz" da Universidade de São Paulo, Piracicaba, SP: transecto na área rural (rosa) e na área suburbana (verde) (adaptado de Gheler-Costa et al., 2002) 
As observações visuais foram realizadas através de censos em uma transeção linear (line transect) (Cullen Júnior, 1997; Krebs, 1989; Ratti \& Garton, 1996; Sutherland, 1996), com limite amostral de $30 \mathrm{~m}$ de largura com 4,5 km de comprimento $\left(0,135 \mathrm{~km}^{2}\right)$ na área rural e 4,7 km de comprimento $\left(0,141 \mathrm{~km}^{2}\right)$ na área suburbana do Campus (860 ha), totalizando 9,2 km de extensão. Esta amostragem representou uma área total de $0,276 \mathrm{~km}^{2}$, ou cerca de $3,2 \%$ do Campus, com $506 \mathrm{~km}$ totais percorridos em 55 dias.

As caminhadas foram realizadas em períodos e trilhas intercaladas durante o dia. Desta forma, no primeiro dia a contagem foi feita em determinado sentido, no período matutino (7:00h às $12: 00 \mathrm{~h}$ ). No dia seguinte a trilha foi percorrida no sentido inverso, no período vespertino (13:00h às 17:00h) e assim por diante durante quinze dias de amostragem, após o que o período amostral de cada trecho foi invertido (Boitani et al., 1995; Beck, 1975). A velocidade média de caminhada foi $2 \mathrm{~km} / \mathrm{h}$ (Emmons, 1984). Este período de tempo permitiu a observação direta dos animais e de vestígios (pegadas, fezes e carcaças), deixados por eles na noite anterior e durante o dia em que estava sendo realizado o percurso na trilha.

Para a análise da abundância de cães e gatos na área, durante as observações diretas (encontros), foram registradas informações com base nas características físicas de cada espécie e indivíduo (raça, pelagem, tamanho, sexo e marcas naturais).

Os levantamentos foram conduzidos por até dois observadores, 0 que permitiu uma maior aproximação dos animais e melhor localização das amostras (Rudran et al., 1996; Cullen Júnior, 1997).

\subsection{Qualificação e Quantificação das Dietas}

A análise fecal foi desenvolvida para ser útil para obtenção de uma descrição básica da dieta de carnívoros e é amplamente utilizada. Porém, até mesmo com uma amostra fecal adequada existem problemas e limitações na 
interpretação dos resultados (Henschel \& Skinner, 1990). Mills (1996) destaca alguns fatores a serem considerados: a) a identificação do pêlo é freqüentemente difícil; b) a quantia de pêlo ingerida por quilograma de alimento varia com as espécies e as partes ingeridas, causando avaliação quantitativa incerta dos dados; e c) a contribuição em termos de biomassa dos vários itens alimentares não pode ser medida e podem ser analisadas somente em uma base de presença ou ausência. Então, itens como roedores, insetos e répteis podem ser superestimados.

No presente estudo as amostras de fezes foram coletadas durante os levantamentos nos transectos e colocadas em saquinhos plásticos identificados. Foram registradas em caderno de campo as coordenadas da localização da amostra com o auxílio de um GPS Garmin etrex® e suas características no momento em que foi encontrada (tamanho, cor e consistência).

Para as análises laboratoriais, as amostras fecais foram manipuladas com luvas e então autoclavadas para a eliminação de ovos de endoparasitas (Green et al., 1986). Predadores são hospedeiros de endoparasitas, vírus e bactérias, que podem infectar os seres humanos por meio de contato direto ou através do ar, sendo por isso indicada à utilização de máscara e luvas descartáveis (Reynolds \& Aebischer, 1991).

Cada amostra foi lavada em água corrente sobre peneira de malha de $1 \mathrm{~mm}$, seca em estufa e separada com o auxílio de um estereoscópio. Os itens foram armazenados em sacos plásticos, identificados pelo número da amostra, juntamente com formol em pastilhas para evitar a infestação por insetos ou fungos (Litvaitis et al., 1996).

As identificações dos itens encontrados durante a análise das fezes, como ossos, dentes, penas, escamas e unhas foram realizadas por meio da comparação com coleções de referência e/ou com material existente no Museu de Zoologia da USP. Para as amostras de pêlos encontradas foram utilizados os métodos de identificação das microestruturas através da visualização da 
medula e da cutícula (Figura 5). Cada espécie de mamífero contém em seus pêlos uma estrutura medular própria, o que permite sua identificação (Teerink, 1991). A medula e suas características internas são bem visíveis quando o pêlo é descolorido em água-oxigenada e depois imerso em óleo de cedro ou bálsamo do Canadá e observado em microscópio.

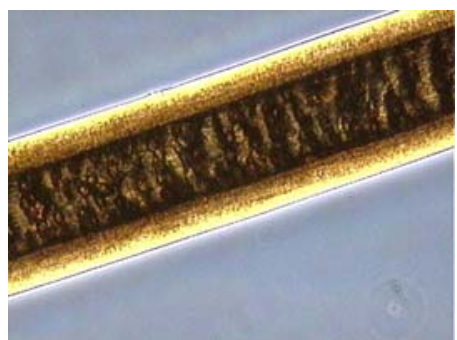

a)

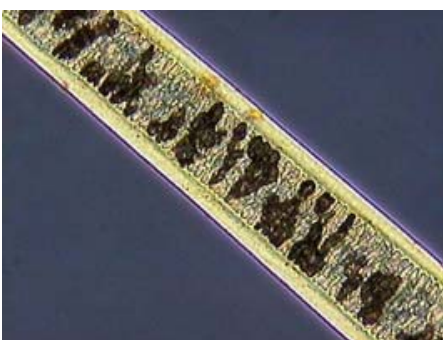

d)

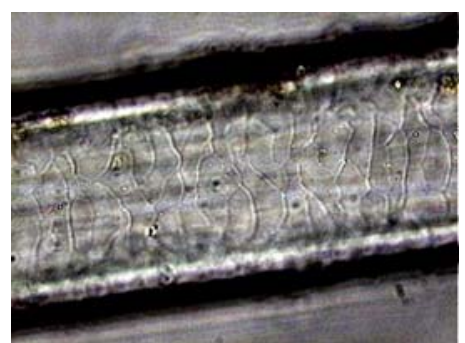

b)

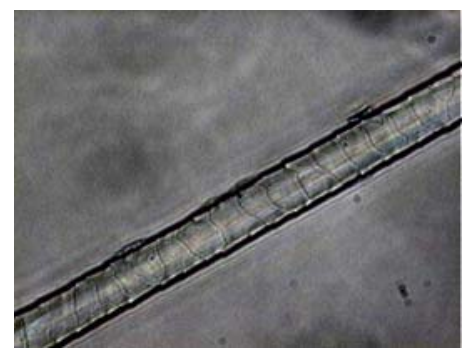

e)

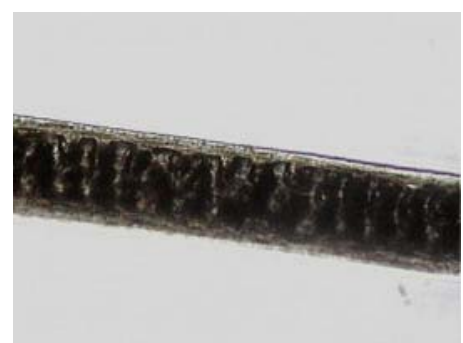

c)

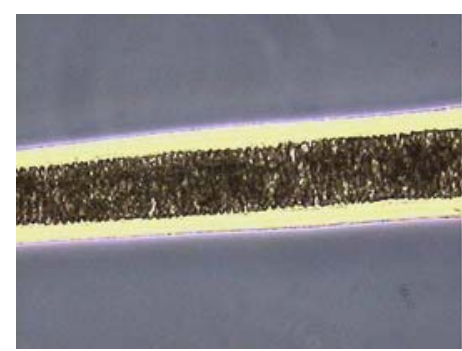

f)

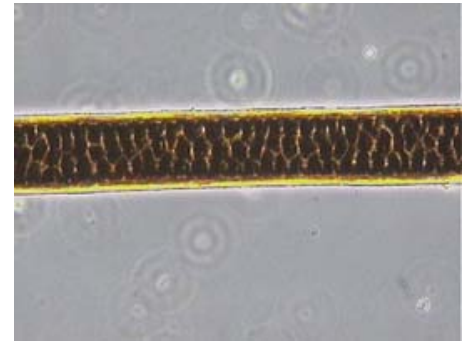

g)

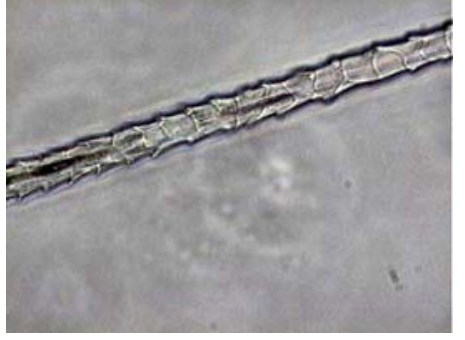

h)

Figura 5 - Fotomicrografias dos padrões microestruturais dos pêlos-guarda de mamíferos: Medula: a) Canis familiaris, c) Calomys spp., d) Felis catus, f) Galictis cuja e g) Olygoryzomys nigripes; Cutícula: b) Canis familiaris, e) Felis catus e h) Olygoryzomys nigripes 
O padrão cuticular dos pêlos pode também ser observado em lâmina sob um microscópio. Para isto, pode-se fazer um molde do pêlo seguindo o seguinte procedimento: a) passar uma fina camada de esmalte de unhas incolor numa lâmina; b) colocar o pêlo sobre o esmalte; c) colocar uma lâmina em cima do pêlo e fazer uma leve pressão para moldar o formato da cutícula; d) retirar cuidadosamente o pêlo; e, e) identificar por comparação sob microscópio (Hausman, 1920; Koonz \& Strandine, 1945; Quadros, 2002; Williams, 1938). As informações taxonômicas e biológicas das espécies foram consultadas em Emmons (1997), Fonseca et al. (1996) e Ruppert \& Barnes (1996).

\subsection{Predação da Fauna Silvestre}

A pressão de predação de cães e gatos errantes sobre a fauna silvestre, foi analisada em função da abundância desses animais na área amostrada, e da quantidade e qualidade das presas identificadas nas amostras fecais de cada espécie, coletadas em todo o período de estudo.

\subsection{Metodologia Analítica}

A abundância dos cães e gatos errantes foi calculada com base na contagem direta dos animais na área amostrada. A densidade estimada foi obtida com base no número de indivíduos por espécie por ambiente (rural e suburbano) e por período (inverno e verão). Para a análise de uso do habitat, a frequência de presença de dada espécie em cada tipo de habitat (rural e suburbano), foi comparada através do Teste T (Zar, 1999; Krebs, 1999).

A qualificação e quantificação dos hábitos alimentares de cães e gatos domésticos foram realizadas conforme sugerido por Bisbal (1986) e Crawshaw (1997), para cada ambiente e período amostrado.

a) Qualidade e quantidade de itens alimentares identificados por espécie; 
b) Frequência relativa de ocorrência (porcentagem do total de fezes em que determinado item foi encontrado) (Garla et al., 2001). A frequência relativa de ocorrência subestima a importância de grandes presas e superestima a importância de pequenas. Porém, tem sido amplamente usada e útil nas comparações de vários estudos (Eberhard, 1954);

c) Porcentagem de ocorrência (número de vezes que um item específico foi encontrado, como porcentagem de todos os itens encontrados). Embora a frequência de ocorrência indique quão comum é um item na dieta, a porcentagem de ocorrência leva em consideração a possibilidade de encontrar mais de um item em uma amostra de fezes (Ackerman et al., 1984);

d) Amplitude do nicho alimentar dos carnívoros: esta medida estima quantitativamente o grau de especialização da dieta de uma espécie, medindo a uniformidade de distribuição de indivíduos entre os recursos (Krebs, 1989, 1999). Segundo Levins (1968), é determinada por:

$$
B=1 /\left(\sum p_{j}^{2}\right), \text { onde: }
$$

$B=$ medida de Levins da amplitude do nicho;

$\mathrm{p}_{\mathrm{j}}=$ proporção dos itens da dieta que são da categoria $\mathrm{j}$ (estimada por número de ocorrências da presa / número total de itens). $B$ varia de 1 a n, sendo n o número total de itens

A medida do nicho pode ser padronizada conforme descrito abaixo numa escala de 0 a 1, para permitir comparações entre estudos com diferentes categorias de presas, já que o valor não padronizado de $B$ aumenta conforme $o$ número de categorias (Krebs, 1999).

$$
\begin{aligned}
& \boldsymbol{B}_{\mathrm{A}}=(\boldsymbol{B}-\mathbf{1}) /(\mathbf{n}-\mathbf{1}), \text { onde: } \\
& B_{\mathrm{A}}=\text { nicho de Levins padronizado; } \\
& B=\text { medida de Levins da amplitude do nicho; } \\
& \mathrm{n}=\text { número possível de itens }
\end{aligned}
$$


$B$ é máximo quando o mesmo número de indivíduos ocorre em cada recurso declarado. Então a espécie não faz discriminação entre os recursos e tem o nicho mais amplo possível (máxima amplitude de nicho, mínima especialização). B é mínimo quando todos os indivíduos ocorrem em somente um recurso declarado (mínima amplitude de nicho, máxima especialização).

e) Grau de sobreposição da dieta, calculado pelo Índice de Pianka (Krebs, 1999; Loveridge \& Macdonald, 2003), conforme descrito abaixo:

$$
\begin{aligned}
& \boldsymbol{O}_{j k}=\left(\boldsymbol{\Sigma} \boldsymbol{p}_{i j} \boldsymbol{p}_{i k}\right) /\left(\sqrt{\boldsymbol{\Sigma}} \boldsymbol{p}_{i j}^{\mathbf{2}} \boldsymbol{\Sigma} \boldsymbol{p}^{\mathbf{2}}{ }_{i k}\right) \text {, onde: } \\
& O_{j k}=\text { medida de sobreposição de Pianka entre as espécies } j \text { e } k \\
& p_{i j}=\text { proporção do recurso } i \text { no total dos recursos usados pela espécie } \\
& \quad j ; \\
& p_{i k}=\text { proporção do recurso } i \text { no total dos recursos usados pela } \\
& \quad \text { espécie } k ; \\
& n=\text { número total de recursos encontrados }
\end{aligned}
$$

Este coeficiente varia de 0 (completa dissimilaridade) a 1 (total similaridade).

f) Biomassa consumida estimada: Número de indivíduos das principais presas presentes nas fezes multiplicado pela média do peso de cada espécie presa da área de estudo (Bueno et al., 2003). Os restos de partes dos corpos das presas encontrados e identificados nas amostras são usados para a contagem do número mínimo de indivíduos consumidos (Emmons, 1987; Motta Junior et al., 1996). Assume-se que houve ingestão completa de presa quando dentes, garras e ossos de todas as partes do esqueleto forem encontradas nas fezes (Motta Junior et al., 1996). Quando há somente pêlos assume-se que apenas um indivíduo foi consumido (Emmons, 1987).

A estimativa da pressão de predação por cães e gatos sobre os mamíferos, foi aferida por meio da biomassa estimada das principais espécies predadas, baseada nos seguintes parâmetros: quantidade de indivíduos por 
espécie de mamífero predada (número de indivíduos encontrado em cada amostra), estimativa do peso médio por indivíduo (adquirida da literatura), frequência de predação (número de vezes que determinada espécie foi encontrada no total de fezes) e a densidade dos predadores (Zar, 1999). 


\section{RESULTADOS}

\subsection{Distribuição e Abundância de Cães e Gatos Errantes}

A estimativa da abundância de cães e gatos errantes na área amostrada foi de 123 animais em todo o período de estudo (Tabela 3). A identificação dos indivíduos, baseada em suas características físicas, permitiu uma estimativa mais precisa do tamanho da população.

Tabela 3. Número de cães e gatos errantes, baseado na identificação das características físicas das duas espécies, durante levantamento no inverno de 2002 e verão de 2003 no Campus "Luiz de Queiroz"

\begin{tabular}{|c|c|c|c|c|c|c|c|c|}
\hline \multirow[b]{2}{*}{ Espécie } & \multicolumn{4}{|c|}{ Inverno $(\mathrm{N}=26)$} & \multicolumn{4}{|c|}{ Verão $(N=29)$} \\
\hline & Macho & Fêmea & n.i. & Total & Macho & Fêmea & n.i. & Total \\
\hline C. familiaris & 12 & 9 & 0 & 21 & 13 & 8 & 0 & 21 \\
\hline F. catus & 8 & 21 & 21 & 50 & 7 & 20 & 4 & 31 \\
\hline Total & 20 & 30 & 21 & 71 & 20 & 28 & 4 & 52 \\
\hline
\end{tabular}

A estimativa de densidade de cães e gatos no período de estudo foi de 445,65 animais $/ \mathrm{km}^{2}$. Os gatos apresentaram maiores densidades tanto no inverno como no verão (181,15 ind./km² e 112,31 ind./km², repectivamente) em relação aos cães (76,08 ind./km² tanto no inverno quanto no verão). 


\subsection{Uso do Habitat}

Cães e gatos errantes são mais abundantes em ambiente suburbano que rural $(T=3,78, p<0,001, N=55 ; T=8,38, p<0,001, N=55$ respectivamente). Os gatos são mais abundantes que cães em ambiente suburbano $(T=6,76$, $\mathrm{p}<0,001, N=55)$ (Figuras 6 e 7), porém não há diferença significativa quanto à abundância de cães e gatos em ambiente rural ( $T=0,82, p=0,46, N=55)$ (Tabela 4).

O maior número de encontros foi registrado com gatos no inverno, na área suburbana (média de 4,57 gatos avistados por dia), e o menor número, também para gatos, foi no verão, na área rural (média de 0,10 gatos avistados por dia).

Tabela 4. Número total de cães e gatos errantes avistados durante levantamento no inverno de 2002 e verão de 2003 nas áreas rural e suburbana do Campus "Luiz de Queiroz"

\begin{tabular}{lcccccc}
\hline & \multicolumn{3}{c}{ Inverno $(\mathrm{N}=26)$} & \multicolumn{3}{c}{ Verão $(\mathrm{N}=29)$} \\
Espécie & Rural & Suburbana & Total & \multicolumn{2}{c}{ Rural } & Suburbana \\
\hline C. familiaris & 14 & 24 & 38 & 9 & 58 & 67 \\
F. catus & 31 & 119 & 150 & 3 & 115 & 118 \\
Total & $\mathbf{4 5}$ & $\mathbf{1 4 3}$ & $\mathbf{1 8 8}$ & $\mathbf{1 2}$ & $\mathbf{1 7 3}$ & $\mathbf{1 8 5}$ \\
\hline
\end{tabular}

$\mathrm{N}=$ número de dias de coleta 


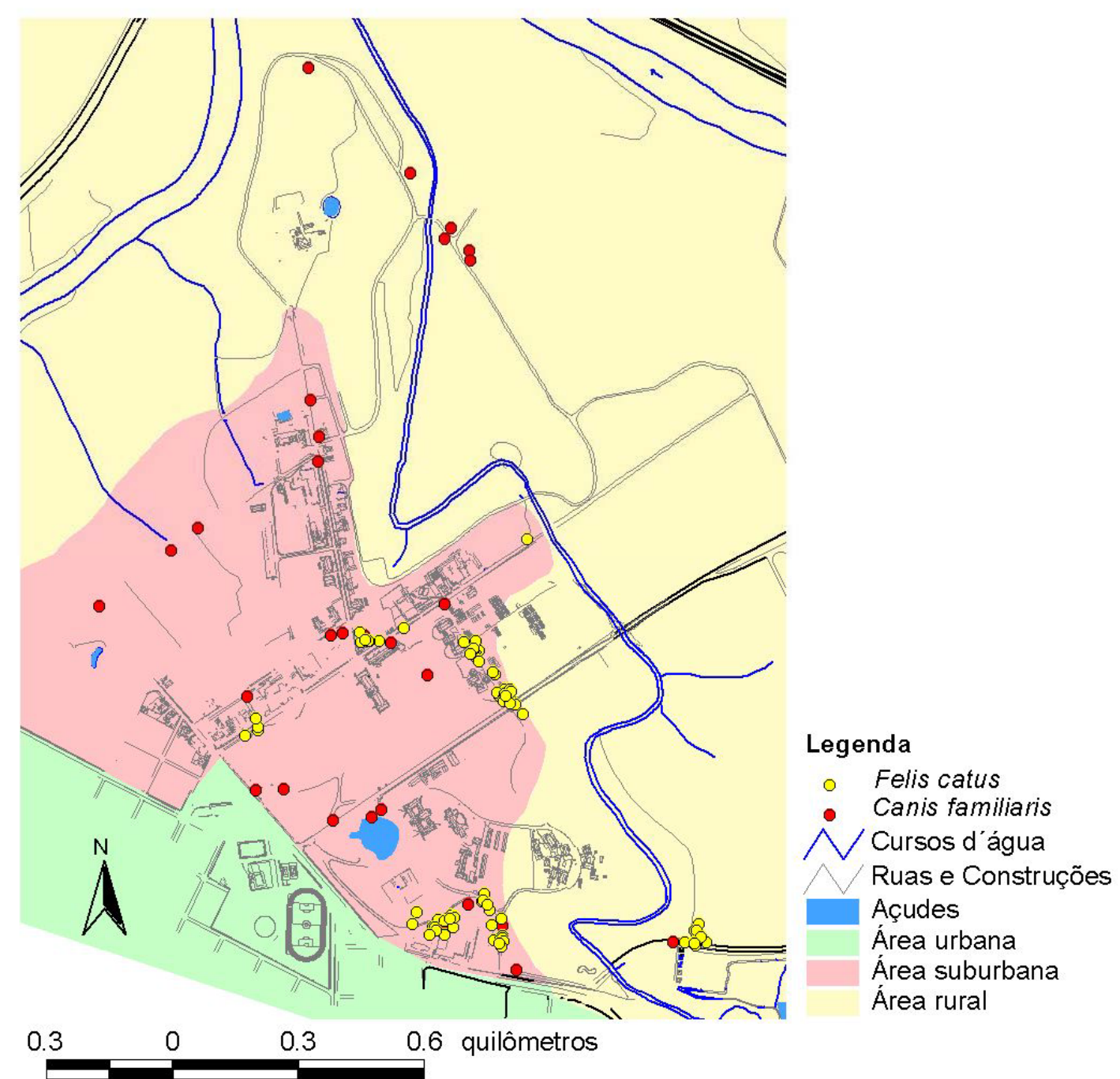

Figura 6 - Localização dos cães (Canis familiairs) e gatos (Felis catus) durante o levantamento no mês de julho de 2002 no Campus "Luiz de Queiroz" da Universidade de São Paulo 


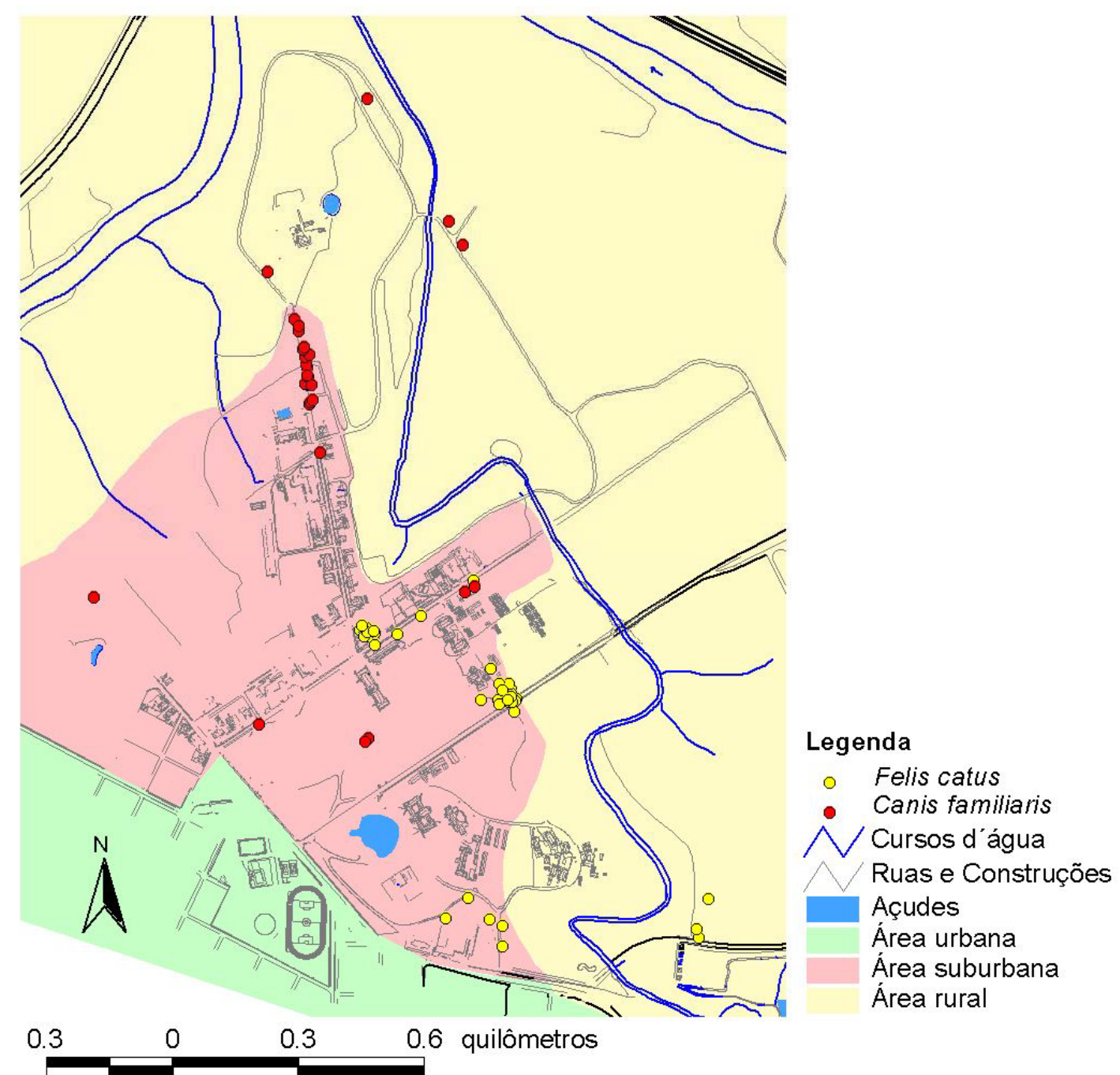

Figura 7 - Localização dos cães (Canis familiairs) e gatos (Felis catus) durante 0 levantamento no mês de janeiro de 2003 no Campus "Luiz de Queiroz" da Universidade de São Paulo 


\subsection{Qualificação e Quantificação da Dieta}

As coletas de fezes resultaram em 238 amostras. No entanto, quatro foram desconsideradas por não conterem pêlos ou outros vestígios que indicassem se pertenciam à cães ou gatos. Sendo assim, 234 amostras de fezes foram analisadas e distribuídas em 147 amostras para o inverno e 87 para o verão, divididas em 137 para cães (99 de inverno e 48 de verão) e 97 para gatos (48 de inverno e 49 de verão).

As análises das 234 amostras de fezes detectaram 1212 ocorrências de 57 itens (68,4\% de origem animal, 15,8\% de origem vegetal e 15,8\% de itens não alimentares) (Tabela 5). Com base na análise da frequência relativa de ocorrência geral dos grupos detectados nas fezes, o material vegetal foi consumido mais frequentemente (27,92\%), seguido por invertebrados $(20,54 \%)$, frutos $(16,11 \%)$, itens não alimentares $(10,82 \%)$, vertebrados indefinidos $(10,7 \%)$, mamíferos $(8 \%)$, aves $(5,16 \%)$, répteis $(0,5 \%)$ e peixes $(0,25 \%)$.

Considerando classes de vertebrados, os mamíferos foram o grupo mais predado, representando $57,52 \%$ do total de itens consumidos, seguidos por aves $(37,17 \%)$, répteis $(3,54 \%)$ e peixes $(1,77 \%)$. Se considerarmos os vertebrados indefinidos, este item representaria 43,5\%, mas não foi possível identificar a quais espécies pertenciam os fragmentos de ossos agrupados neste item, pois as respectivas amostras não continham outros vestígios que pudessem auxiliar na identificação. Entre os mamíferos, a ordem Rodentia foi mais frequente nas fezes (42,31\%), seguida de Didelphimorphia (21,79\%), Carnivora (19,23\%), Lagomorpha (7,69\%), mamíferos indefinidos (5,13\%) e Xenarthra (3,85\%) (Tabela 5). 
Tabela 5. Itens encontrados em 234 amostras de fezes de cães e gatos errantes coletadas durante o inverno de 2002 e verão de 2003 no Campus "Luiz de Queiroz"

\begin{tabular}{|c|c|c|c|c|c|c|c|c|c|c|c|c|c|c|c|c|c|c|}
\hline \multirow[b]{3}{*}{ ITEM } & \multicolumn{6}{|c|}{ INVERNO (N=147) } & \multicolumn{6}{|c|}{ VERÃO (N=87) } & \multicolumn{6}{|c|}{ TOTAL (N=234) } \\
\hline & \multicolumn{3}{|c|}{$\begin{array}{c}\text { Canis familiaris } \\
\qquad(\mathrm{N}=99)\end{array}$} & \multicolumn{3}{|c|}{$\begin{array}{c}\text { Felis catus } \\
(\mathrm{N}=48)\end{array}$} & \multicolumn{3}{|c|}{$\begin{array}{l}\text { Canis familiaris } \\
\qquad(\mathrm{N}=38)\end{array}$} & \multicolumn{3}{|c|}{$\begin{array}{c}\text { Felis catus } \\
(\mathrm{N}=49)\end{array}$} & \multicolumn{3}{|c|}{$\begin{array}{l}\text { Canis familiaris } \\
\qquad(\mathrm{N}=137)\end{array}$} & \multicolumn{3}{|c|}{$\begin{array}{l}\text { Felis catus } \\
(\mathrm{N}=97)\end{array}$} \\
\hline & $\mathrm{n}$ & $\mathrm{Fr}$ & $\%$ & $\mathrm{n}$ & $\mathrm{Fr}$ & $\%$ & $\mathrm{n}$ & $\mathrm{Fr}$ & $\%$ & $\mathrm{n}$ & $\mathrm{Fr}$ & $\%$ & $\mathrm{n}$ & $\mathrm{Fr}$ & $\%$ & $\mathrm{n}$ & $\mathrm{Fr}$ & $\%$ \\
\hline \multicolumn{19}{|l|}{$\begin{array}{l}\text { Invertebrados } \\
\text { Ordens }\end{array}$} \\
\hline Coleoptera & 22 & 22,22 & 4,28 & 14 & 29,16 & 6,54 & 14 & 36,84 & 6,86 & 17 & 34,69 & 6,07 & 36 & 26,27 & 5,01 & 31 & 31,96 & 6,27 \\
\hline Dermaptera & 1 & 1,01 & 0,19 & - & - & - & 3 & 7,90 & 1,47 & 8 & 16,32 & 2,85 & 4 & 2,92 & 0,56 & 8 & 8,25 & 1,61 \\
\hline Diptera & 4 & 4,04 & 0,77 & 4 & 8,33 & 1,87 & 1 & 2,63 & 0,49 & 2 & 4,08 & 0,71 & 5 & 3,64 & 0,70 & 6 & 6,19 & 1,21 \\
\hline Hemiptera & 3 & 3,03 & 0,58 & 1 & 2,08 & 0,46 & 1 & 2,63 & 0,49 & 1 & 2,04 & 0,35 & 4 & 2,92 & 0,56 & 2 & 2,06 & 0,40 \\
\hline Hymenoptera & 54 & 54,54 & 10,50 & 21 & 43,75 & 9,81 & 26 & 68,42 & 12,74 & 36 & 73,46 & 12,85 & 80 & 58,39 & 11,14 & 57 & 58,76 & 11,53 \\
\hline Isoptera & 3 & 3,03 & 0,58 & - & - & - & - & - & - & 3 & 6,12 & 1,07 & 3 & 2,19 & 0,41 & 3 & 3,09 & 0,60 \\
\hline Lepdoptera & - & - & - & - & - & - & - & - & - & 2 & 4,08 & 0,71 & - & - & - & 2 & 2,06 & 0,40 \\
\hline Mantodea & - & - & - & - & - & - & - & - & - & 1 & 2,04 & 0,35 & - & - & - & 1 & 1,03 & 0,20 \\
\hline Orthoptera & 3 & 3,03 & 0,58 & 6 & 12,50 & 2,80 & 1 & 2,63 & 0,49 & 8 & 16,32 & 2,85 & 4 & 2,92 & 0,56 & 14 & 14,43 & 2,83 \\
\hline Siphonaptera & 1 & 1,01 & 0,19 & - & - & - & 1 & 2,63 & 0,49 & 2 & 4,08 & 0,71 & 2 & 1,45 & 0,27 & 2 & 2,06 & 0,40 \\
\hline Acari & 5 & 5,05 & 0,98 & 8 & 16,66 & 3,73 & - & - & - & 3 & 6,12 & 1,07 & 5 & 3,64 & 0,70 & 11 & 11,34 & 2,22 \\
\hline Isopoda & 3 & 3,03 & 0,58 & - & - & - & 2 & 5,26 & 0,98 & 3 & 6,12 & 1,07 & 5 & 3,64 & 0,70 & 3 & 3,09 & 0,60 \\
\hline Crustáceos indef. & - & - & - & - & - & - & - & - & - & 1 & 2,04 & 0,35 & - & - & - & 1 & 1,03 & 0,20 \\
\hline Stylommatophora & 2 & 2,02 & 0,38 & - & - & - & 2 & 5,26 & 0,98 & 6 & 12,24 & 2,14 & 4 & 2,92 & 0,56 & 6 & 6,19 & 1,21 \\
\hline Invertebr. Indef. & 19 & 19,19 & 3,69 & 9 & 18,75 & 4,20 & 11 & 28,94 & 5,39 & 14 & 28,57 & 5 & 30 & 21,89 & 4,18 & 23 & 23,71 & 4,65 \\
\hline Répteis & 2 & 2,02 & 0,38 & 1 & 2,08 & 0,46 & - & - & - & 1 & 2,04 & 0,35 & 2 & 1,45 & 0,27 & 2 & 2,06 & 0,40 \\
\hline \multicolumn{19}{|l|}{ Aves } \\
\hline Aves diversas & 21 & 21,21 & 4,08 & 7 & 14,58 & 3,27 & 6 & 15,78 & 2,94 & 7 & 14,28 & 2,50 & 27 & 19,70 & 3,76 & 14 & 14,43 & 2,83 \\
\hline Casca de ovo & 2 & 2,02 & 0,38 & - & - & - & - & - & - & 2 & 4,08 & 0,71 & 2 & 1,45 & 0,27 & 2 & 2,06 & 0,40 \\
\hline Peixes & - & - & - & 2 & 4,16 & 0,93 & - & - & - & - & - & - & - & - & - & 2 & 2,06 & 0,40 \\
\hline \multicolumn{19}{|l|}{ Mamíferos } \\
\hline \multicolumn{19}{|l|}{ Ordem Rodentia } \\
\hline Família Muridae & 1 & 1,01 & 0,19 & 1 & 2,08 & 0,46 & 2 & 5,26 & 0,98 & - & - & - & 3 & 2,19 & 0,41 & 1 & 1,03 & 0,20 \\
\hline Calomys tener & 2 & 2,02 & 0,38 & - & - & - & - & - & - & - & - & - & 2 & 1,45 & 0,27 & - & - & \\
\hline
\end{tabular}


Tabela 5. Itens encontrados em 234 amostras de fezes de cães e gatos errantes coletadas durante o inverno de 2002 e verão de 2003 no Campus "Luiz de Queiroz"

\begin{tabular}{|c|c|c|c|c|c|c|c|c|c|c|c|c|c|c|c|c|c|c|}
\hline \multirow[b]{3}{*}{ ITEM } & \multicolumn{6}{|c|}{ INVERNO (N=147) } & \multicolumn{6}{|c|}{ VERÃO (N=87) } & \multicolumn{6}{|c|}{ TOTAL (N=234) } \\
\hline & \multicolumn{3}{|c|}{$\begin{array}{l}\text { Canis familiaris } \\
(\mathrm{N}=99)\end{array}$} & \multicolumn{3}{|c|}{$\begin{array}{l}\text { Felis catus } \\
(\mathrm{N}=48)\end{array}$} & \multicolumn{3}{|c|}{$\begin{array}{l}\text { Canis familiaris } \\
\qquad(\mathrm{N}=38)\end{array}$} & \multicolumn{3}{|c|}{$\begin{array}{c}\text { Felis catus } \\
(\mathrm{N}=49)\end{array}$} & \multicolumn{3}{|c|}{$\begin{array}{l}\text { Canis familiaris } \\
\qquad(\mathrm{N}=137)\end{array}$} & \multicolumn{3}{|c|}{$\begin{array}{c}\text { Felis catus } \\
(\mathrm{N}=97)\end{array}$} \\
\hline & $\mathrm{n}$ & $\mathrm{Fr}$ & $\%$ & $\mathrm{n}$ & $\mathrm{Fr}$ & $\%$ & $\mathrm{n}$ & $\mathrm{Fr}$ & $\%$ & $\mathrm{n}$ & $\mathrm{Fr}$ & $\%$ & $\mathrm{n}$ & $\mathrm{Fr}$ & $\%$ & $\mathrm{n}$ & $\mathrm{Fr}$ & $\%$ \\
\hline Família Muridae & 1 & 1,01 & 0,19 & 1 & 2,08 & 0,46 & 2 & 5,26 & 0,98 & - & - & - & 3 & 2,19 & 0,41 & 1 & 1,03 & 0,20 \\
\hline $\begin{array}{l}\text { Calomys tener } \\
\text { Olygoryzomys }\end{array}$ & 2 & 2,02 & 0,38 & - & - & - & - & - & - & - & - & - & 2 & 1,45 & 0,27 & - & - & \\
\hline nigripes & - & - & - & 3 & 6,25 & 1,40 & - & - & - & - & - & - & - & - & - & 3 & 3,09 & 0,60 \\
\hline Subfam. Murinae & 1 & 1,01 & 0,19 & 1 & 2,08 & 0,46 & - & - & - & 1 & 2,04 & 0,35 & 1 & 0,72 & 0,13 & 2 & 2,06 & 0,40 \\
\hline Mus musculus & 1 & 1,01 & 0,19 & - & - & - & 2 & 5,26 & 0,98 & - & - & - & 3 & 2,19 & 0,41 & - & - & - \\
\hline Rattus novergicus & - & - & - & - & - & - & 1 & 2,63 & 0,49 & - & - & - & 1 & 0,72 & 0,13 & - & - & - \\
\hline Rattus rattus & - & - & - & - & - & - & 1 & 2,63 & 0,49 & - & - & - & 1 & 0,72 & 0,13 & - & - & - \\
\hline $\begin{array}{r}\text { Cavia aperea } \\
\text { Coendou }\end{array}$ & 2 & 2,02 & 0,38 & 2 & 4,16 & 0,93 & 1 & 2,63 & 0,49 & 2 & 4,08 & 0,71 & 3 & 2,19 & 0,41 & 4 & 4,12 & 0,80 \\
\hline $\begin{array}{r}\text { prehensilis } \\
\text { Hydrochoerus }\end{array}$ & - & - & - & - & - & - & 2 & 5,26 & 0,98 & - & - & - & 2 & 1,45 & 0,27 & - & - & - \\
\hline $\begin{array}{r}\text { hydrochaeris } \\
\text { Myocastor }\end{array}$ & 1 & 1,01 & 0,19 & - & - & - & - & - & - & - & - & - & 1 & 0,72 & 0,13 & - & - & - \\
\hline coypus & 3 & 3,03 & 0,58 & - & - & - & 3 & 7,90 & 1,47 & - & - & - & 6 & 4,37 & 0,83 & - & - & - \\
\hline $\begin{array}{l}\text { Didelphimorphia } \\
\text { Família }\end{array}$ & & & & & & & & & & & & & & & & & & \\
\hline $\begin{array}{r}\text { Didelphidae } \\
\text { Didelphis }\end{array}$ & 1 & 1,01 & 0,19 & 1 & 2,08 & 0,46 & 1 & 2,63 & 0,49 & 4 & 8,16 & 1,42 & 2 & 1,45 & 0,27 & 5 & 5,15 & 1,00 \\
\hline $\begin{array}{l}\text { albiventris } \\
\text { Lutreolina }\end{array}$ & 1 & 1,01 & 0,19 & 2 & 4,16 & 0,93 & 3 & 7,90 & 1,47 & - & - & - & 4 & 2,92 & 0,56 & 2 & 2,06 & 0,40 \\
\hline $\begin{array}{l}\text { crassicaudata } \\
\text { Ordem Carnívora }\end{array}$ & 1 & 1,01 & 0,19 & 1 & 2,08 & 0,46 & 1 & 2,63 & 0,49 & 1 & 2,04 & 0,35 & 2 & 1,45 & 0,27 & 2 & 2,06 & 0,40 \\
\hline Nasua nasua & 6 & 6,06 & 1,16 & - & - & - & 2 & 5,26 & 0,98 & - & - & - & 8 & 5,84 & 1,11 & - & - & - \\
\hline Galictis cuja & 3 & 3,03 & 0,58 & 1 & 2,08 & 0,46 & 1 & 2,63 & 0,49 & 2 & 4,08 & 0,71 & 4 & 2,92 & 0,56 & 3 & 3,09 & 0,60 \\
\hline
\end{tabular}


Tabela 5. Itens encontrados em 234 amostras de fezes de cães e gatos errantes coletadas durante o inverno de 2002 e verão de 2003 no Campus "Luiz de Queiroz"

\begin{tabular}{|c|c|c|c|c|c|c|c|c|c|c|c|c|c|c|c|c|c|c|}
\hline \multirow[b]{3}{*}{ ITEM } & \multicolumn{6}{|c|}{ INVERNO (N=147) } & \multicolumn{6}{|c|}{ VERÃO (N=87) } & \multicolumn{6}{|c|}{ TOTAL (N=234) } \\
\hline & \multicolumn{3}{|c|}{$\begin{array}{l}\text { Canis familiaris } \\
\qquad(\mathrm{N}=99)\end{array}$} & \multicolumn{3}{|c|}{$\begin{array}{l}\text { Felis catus } \\
(\mathrm{N}=48)\end{array}$} & \multicolumn{3}{|c|}{$\begin{array}{l}\text { Canis familiaris } \\
\qquad(\mathrm{N}=38)\end{array}$} & \multicolumn{3}{|c|}{$\begin{array}{l}\text { Felis catus } \\
(\mathrm{N}=49)\end{array}$} & \multicolumn{3}{|c|}{$\begin{array}{l}\text { Canis familiaris } \\
\quad(\mathrm{N}=137)\end{array}$} & \multicolumn{3}{|c|}{$\begin{array}{c}\text { Felis catus } \\
(\mathrm{N}=97)\end{array}$} \\
\hline & $\mathrm{n}$ & $\mathrm{Fr}$ & $\%$ & $\mathrm{n}$ & $\mathrm{Fr}$ & $\%$ & $\mathrm{n}$ & Fr & $\%$ & $\mathrm{n}$ & $\mathrm{Fr}$ & $\%$ & $\mathrm{n}$ & $\mathrm{Fr}$ & $\%$ & $\mathrm{n}$ & $\mathrm{Fr}$ & $\%$ \\
\hline \multicolumn{19}{|l|}{ Ordem } \\
\hline \multicolumn{19}{|l|}{ Lagomorpha } \\
\hline Leporidae & 1 & 1,01 & 0,19 & 1 & 2,08 & 0,46 & 2 & 5,26 & 0,98 & 2 & 4,08 & 0,71 & 3 & 2,19 & 0,41 & 3 & 3,09 & 0,60 \\
\hline \multicolumn{19}{|l|}{ Ordem Xenarthra } \\
\hline Dasypus & & & & & & & & & & & & & & & & & & \\
\hline novemcinctus & 2 & 2,02 & 0,38 & 1 & 2,08 & 0,46 & - & - & - & - & - & - & 2 & 1,45 & 0,27 & 1 & 1,03 & 0,20 \\
\hline Mamíferos Indef. & 1 & 1,01 & 0,19 & - & - & - & 2 & 5,26 & 0,98 & 1 & 2,04 & 0,35 & 3 & 2,19 & 0,41 & 1 & 1,03 & 0,20 \\
\hline \multicolumn{19}{|l|}{ Material Vegetal } \\
\hline Arroz & 4 & 4,04 & 0,77 & 1 & 2,08 & 0,46 & - & - & - & 1 & 2,04 & 0,35 & 4 & 2,92 & 0,56 & 2 & 2,06 & 0,40 \\
\hline Milho & 3 & 3,03 & 0,58 & 1 & 2,08 & 0,46 & 7 & 18,42 & 3,43 & 1 & 2,04 & 0,35 & 10 & 7,29 & 1,39 & 2 & 2,06 & 0,40 \\
\hline Feijão & 17 & 17,17 & 3,30 & 6 & 12,50 & 2,80 & 10 & 26,31 & 4,90 & 7 & 14,28 & 2,50 & 27 & 19,70 & 3,76 & 13 & 13,40 & 2,63 \\
\hline Grama & 72 & 72,72 & 14 & 23 & 47,91 & 10,74 & 15 & 39,47 & 7,35 & 20 & 40,81 & 7,14 & 87 & 63,50 & 12,12 & 43 & 44,33 & 8,7 \\
\hline \multicolumn{18}{|c|}{$\begin{array}{l}\text { Outros (gravetos, } \\
\text { folhas dicotil.) } 93\end{array}$} & 18 \\
\hline \multicolumn{19}{|l|}{ Frutos } \\
\hline Coquinho & 1 & 1,01 & 0,19 & 1 & 2,08 & 0,46 & - & - & - & 2 & 4,08 & 0,71 & 1 & 0,72 & 0,13 & 3 & 3,09 & 060 \\
\hline Mamão & 1 & 1,01 & 0,19 & - & - & - & - & - & - & - & - & - & 1 & 0,72 & 0,13 & - & - & - \\
\hline Melancia & 4 & 4,04 & 0,77 & - & - & - & - & - & - & - & - & - & 4 & 2,92 & 0,56 & - & - & - \\
\hline Fruto Indef. & 40 & 40,04 & 7,78 & 16 & 33,33 & 7,47 & 17 & 44,73 & 8,33 & 31 & 63,26 & 11,07 & 57 & 41,6 & 7,94 & 47 & 48,45 & 9,5 \\
\hline \multicolumn{19}{|c|}{ Não alimentar } \\
\hline Anilha & 1 & 1,01 & 0,19 & - & - & - & - & - & - & - & - & - & 1 & 0,72 & 0,13 & - & - & - \\
\hline Esponja & 2 & 2,02 & 0,38 & - & - & - & 1 & 2,63 & 0,49 & - & - & - & 3 & 2,19 & 0,41 & - & - & - \\
\hline Filtro de cigarro & 1 & 1,01 & 0,19 & - & - & - & - & - & - & - & - & - & 1 & 0,72 & 0,13 & - & - & - \\
\hline
\end{tabular}


Tabela 5. Itens encontrados em 234 amostras de fezes de cães e gatos errantes coletadas durante o inverno de 2002 e verão de 2003 no Campus "Luiz de Queiroz"

\begin{tabular}{|c|c|c|c|c|c|c|c|c|c|c|c|c|c|c|c|c|c|c|}
\hline \multirow[b]{3}{*}{ ITEM } & \multicolumn{6}{|c|}{ INVERNO (N=147) } & \multicolumn{6}{|c|}{ VERÃO (N=87) } & \multicolumn{6}{|c|}{ TOTAL (N=234) } \\
\hline & \multicolumn{3}{|c|}{$\begin{array}{l}\text { Canis familiaris } \\
\qquad(\mathrm{N}=99)\end{array}$} & \multicolumn{3}{|c|}{$\begin{array}{l}\text { Felis catus } \\
(\mathrm{N}=48)\end{array}$} & \multicolumn{3}{|c|}{$\begin{array}{l}\text { Canis familiaris } \\
\qquad(\mathrm{N}=38)\end{array}$} & \multicolumn{3}{|c|}{$\begin{array}{l}\text { Felis catus } \\
(\mathrm{N}=49)\end{array}$} & \multicolumn{3}{|c|}{$\begin{array}{l}\text { Canis familiaris } \\
\qquad(\mathrm{N}=137)\end{array}$} & \multicolumn{3}{|c|}{$\begin{array}{c}\text { Felis catus } \\
(\mathrm{N}=97)\end{array}$} \\
\hline & $\mathrm{n}$ & $\mathrm{Fr}$ & $\%$ & $\mathrm{n}$ & Fr & $\%$ & $\mathrm{n}$ & Fr & $\%$ & $\mathrm{n}$ & $\mathrm{Fr}$ & $\%$ & $\mathrm{n}$ & $\mathrm{Fr}$ & $\%$ & $\mathrm{n}$ & $\mathrm{Fr}$ & $\%$ \\
\hline Linha & 17 & 17,17 & 3,30 & 2 & 4,16 & 0,93 & 2 & 5,26 & 0,98 & 4 & 8,16 & 1,42 & 19 & 13,86 & 2,65 & 6 & 6,19 & 1,21 \\
\hline Papel & 10 & 10,10 & 1,94 & 4 & 8,33 & 1,87 & 4 & 10,52 & 1,96 & 5 & 10,20 & 1,78 & 14 & 10,21 & 0,19 & 9 & 9,28 & 1,82 \\
\hline Papel alumínio & 5 & 5,05 & 0,98 & - & - & - & 1 & 2,63 & 0,49 & 1 & 2,04 & 0,35 & 6 & 4,37 & 0,83 & 1 & 1,03 & 0,20 \\
\hline Pedras & 6 & 6,06 & 1,16 & 6 & 12,50 & 2,80 & 6 & 15,78 & 2,94 & 16 & 32,65 & 5,71 & 12 & 8,75 & 1,67 & 22 & 22,68 & 4,45 \\
\hline Plástico & 8 & 8,08 & 1,55 & 4 & 8,33 & 1,87 & 2 & 5,26 & 0,98 & 2 & 4,08 & 0,71 & 10 & 7,29 & 1,39 & 6 & 6,19 & 1,21 \\
\hline Indefinido & 10 & 10,10 & 1,94 & 1 & 2,08 & 0,46 & 1 & 2,63 & 0,49 & 3 & 6,12 & 1,07 & 11 & 8,02 & 1,53 & 4 & 4,12 & 0,80 \\
\hline Tot. Ocorrências & 514 & & 99,76 & 214 & & 99,83 & 204 & & 99,96 & 280 & & 99,81 & 718 & & 98,05 & 494 & & 104 \\
\hline
\end{tabular}

$\mathrm{N}=$ número de fezes analisadas; $n=$ número de fezes contendo o item; Fr = freqüência de ocorrência de um item no total de fezes; \% = porcentagem de ocorrência de um item específico em relação a todos os itens; indef. = indefinido; Invertebr. = Invertebrados; Subfam. = Subfamília; Vertebr. = Vertebrados; dicotil. = dicotiledônea; Tot. = Total 


\subsubsection{Análise da Dieta dos Cães Errantes}

Foram analisadas 137 amostras de fezes de cães (99 de inverno e 38 de verão), onde foram identificados 52 itens, 34 de origem animal (65,38\%), nove de origem vegetal $(17,31 \%)$ e nove itens não alimentares $(17,31 \%)$. Nas amostras de inverno, foram identificados 49 itens, 31 de origem animal $(63,26 \%)$, nove de origem vegetal $(18,37 \%)$ e nove itens não alimentares $(18,37 \%)$. Neste período, o material vegetal foi o item mais freqüente nas fezes, representando $28 \%$ das ocorrências dos itens encontrados seguido de invertebrados (18\%) (Figura 9a). Nas amostras do verão, foram identificados 38 itens, 26 de origem animal (68,42\%), sete itens não alimentares (18,42\%) e cinco de origem vegetal $(13,16 \%)$. Neste período, o material vegetal também foi o item mais freqüente, representando $27,61 \%$ das ocorrências, seguido de invertebrados (22,38\%) (Figura 9b). Considerando os itens de origem animal dos dois períodos os invertebrados foram os mais consumidos $(57,05 \%)$ seguidos de mamíferos (25,15\%), aves (16,56\%) e répteis $(1,23 \%)$.
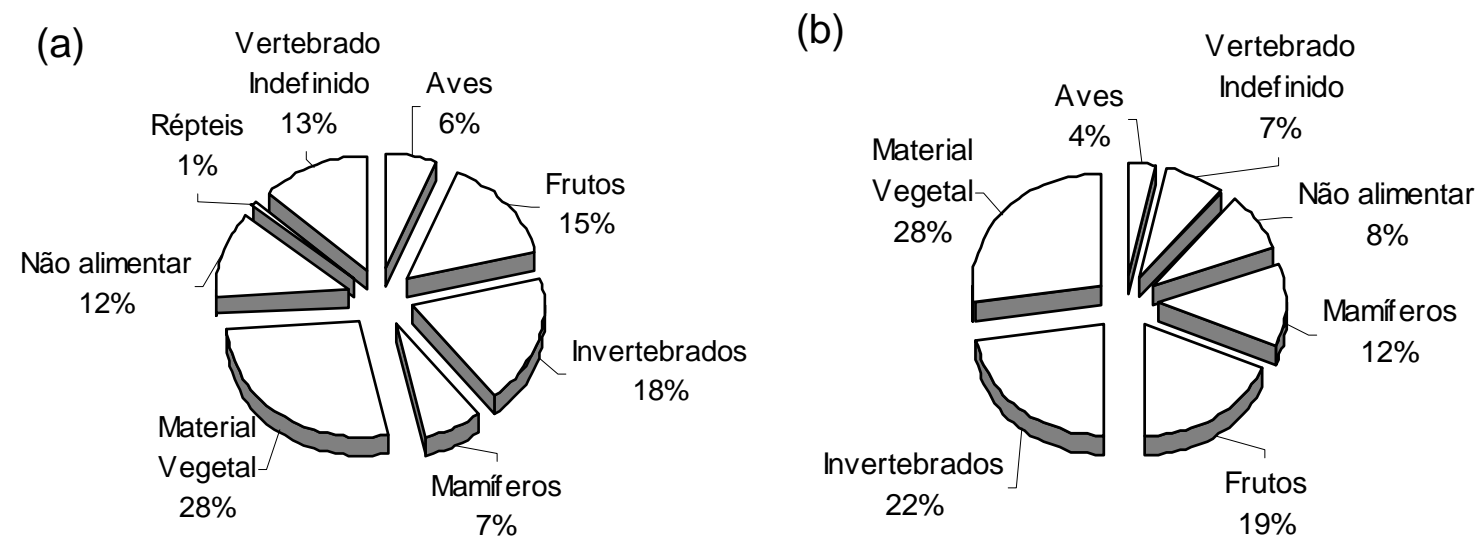

Figura 8 - Frequência relativa de ocorrência dos itens encontrados nas amostras de fezes de cães errantes coletadas no Campus "Luiz de Queiroz": a) inverno de 2002 ( $N=99)$ e b) verão de 2003 ( $N=38)$ 


\subsubsection{Análise da Dieta dos Gatos Errantes}

Foram analisadas 97 amostras de fezes de gatos errantes, onde foram identificados 44 itens, 31 de origem animal (70,45\%), sete de origem vegetal $(15,90 \%)$ e seis itens não alimentares (13,64\%). Nas amostras do inverno foram identificados 21 itens de origem animal $(63,64 \%)$, sete de origem vegetal $(21,21 \%)$ e cinco itens não alimentares (15,15\%). Neste período, o material vegetal foi o item mais freqüente, representando $30,4 \%$ das ocorrências dos itens, seguido de invertebrados (20,27\%) (Figura 10a). Nas amostras do verão, foram identificados 26 itens de origem animal $(66,67 \%)$, sete de origem vegetal $(17,95 \%)$ e seis itens não alimentares $(15,38 \%)$. Neste período o material vegetal foi o item mais freqüente, representando $25,96 \%$ das ocorrências, seguido de invertebrados (24,30\%) (Figura 10b). Considerando os itens de origem animal dos dois períodos os invertebrados foram os mais freqüentes $(63,24 \%)$, seguidos de mamíferos $(20,51 \%)$, aves $(12,82 \%)$, peixes e répteis $(1,7 \%$ cada).

(a)

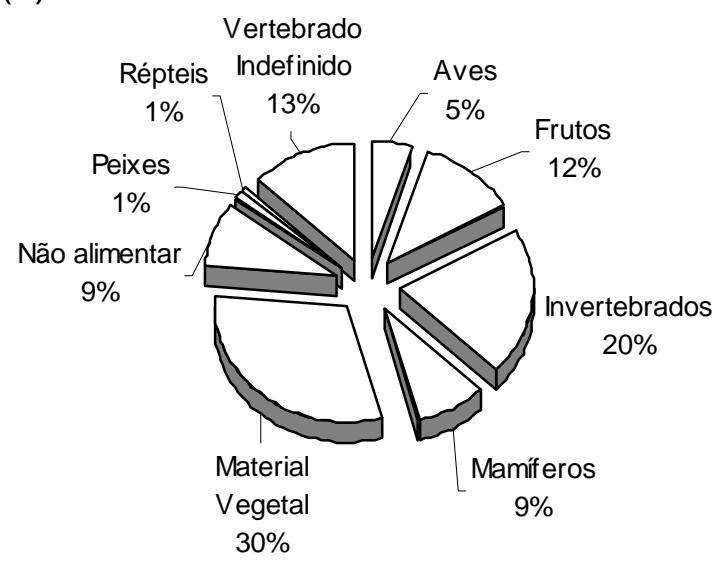

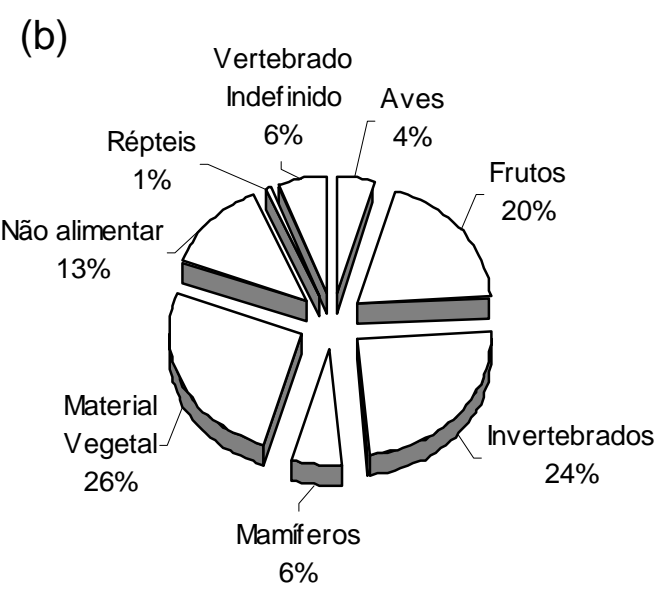

Figura 9 - Frequência relativa de ocorrência dos itens encontrados nas amostras de fezes de gatos errantes coletadas no Campus "Luiz de Queiroz": a) inverno de $2002(\mathrm{~N}=48)$ e b) verão de 2003 ( $N=49)$ 


\subsubsection{Amplitude e Sobreposição do Nicho Alimentar}

A amplitude do nicho $(B)$ calculada sobre a freqüência relativa de ocorrência total dos itens encontrados nas fezes de cães e gatos errantes, apresentou resultados próximos para as duas espécies, ou seja, cães $B=0,4463$ e gatos $B=0,4892$ (Tabela 6). A sobreposição do nicho (O) apresentou aproximadamente 97\% para inverno, verão e ambos, resultado muito próximo da completa sobreposição (Tabela 7). Não há diferença significativa quanto as dietas de cães e gatos do inverno $\left(X^{2}=6,43\right.$; g.l. 7 ; $\left.P=0,49\right)$, verão $\left(X^{2}=4,19\right.$; g.l. $6 ; P=0,65)$ e ambos os períodos $\left(X^{2}=6,18\right.$; g.l. $\left.7 ; P=0,51\right)$.

Tabela 6. Amplitude do nicho alimentar $(B)$ de cães e gatos errantes do Campus "Luiz de Queiroz"

\begin{tabular}{lccc}
\hline & \multicolumn{3}{c}{ Amplitude (B) } \\
Espécies & Inverno & Verão & Total \\
\hline C. familiaris & 0,4276 & 0,4485 & 0,4463 \\
F. catus & 0,5737 & 0,3978 & 0,4892 \\
\hline
\end{tabular}

Tabela 7. Sobreposição do nicho alimentar $(O)$ de cães e gatos errantes do Campus "Luiz de Queiroz"

\begin{tabular}{lccc}
\hline \multirow{2}{*}{ Espécies } & \multicolumn{3}{c}{ Sobreposição (O) } \\
C.familiaris / F.catus & 0,97095 & 0,96411 & 0,97108 \\
\hline
\end{tabular}

\subsubsection{Biomassa Consumida Estimada}

Em relação ao número de indivíduos das espécies de mamíferos consumidas por cães, Nasua nasua foi a espécie mais consumida, respondendo por $17,02 \%$ do total de itens consumidos, seguida de Myocastor 
coypus (12,76\%). Nas análises das amostras de inverno $N$. nasua representou $24 \%$ dos itens consumidos seguido de Galictis cuja e M. coypus com $12 \%$ cada. No entanto no verão, Didelphis albiventris e $M$. coypus foram os mais consumidos (13,65\% cada), seguidos de Coendou prehensilis, Muridae n.i., Mus musculus e Leporidae (9,09\% cada).

Quanto à biomassa consumida estimada no inverno foi estimado um consumo de $59,33 \mathrm{~kg}$, sendo que $N$. nasua representou $50,1 \%$, seguido de $M$. coypus $(21,2 \%)$ e Dasypus novemcinctus $(12,3 \%)$. No verão $(39,12 \mathrm{~kg}), M$. coypus representou $32,13 \%$, seguido de $N$. nasua $(25,56 \%)$ e $C$. prehensilis $(17,17 \%)$ (Tabela 8).

Quanto às espécies de mamíferos consumidas por gatos, Didelphidae n.i. foi mais consumido, respondendo por $19,23 \%$ do total de itens consumidos, seguido de Cavia aperea (15,38\%). No inverno Olygoryzomys nigripes foi a espécie mais consumida $(21,43 \%)$, seguida de $D$. novemcinctus e D. albiventris $(14,29 \%$ cada). No entanto no verão, Didelphidae n.i. foi mais consumida (33,33\%), seguida de C. aperea, G. cuja e Leporidae (16,67\% cada). Quanto à biomassa consumida estimada no inverno $(11,21 \mathrm{~kg}), D$. novemcinctus representou $32,53 \%$ seguido de $D$. albiventris $(22,30 \%)$ e G. cuja $(14,08 \%)$ e no verão $(10,20 \mathrm{~kg})$, Didelphidae n.i. representou $36,85 \%$, seguido por G. cuja (30,97\%) e Leporide (18,3\%) (Tabela 9). 
Tabela 8. Biomassa consumida estimada das espécies de mamíferos identificadas em 137 amostras de fezes de cães errantes coletadas no Campus "Luiz de Queiroz"

\begin{tabular}{|c|c|c|c|c|c|c|c|c|c|}
\hline \multirow[b]{3}{*}{ Espécies presas } & \multirow{3}{*}{$\begin{array}{c}\text { Peso } \\
\text { médio } \\
(\mathrm{g})\end{array}$} & \multicolumn{4}{|c|}{ Inverno $(\mathrm{N}=99)$} & \multicolumn{4}{|c|}{ Verão $(\mathrm{N}=38)$} \\
\hline & & \multicolumn{2}{|c|}{$\begin{array}{l}\text { Número } \\
\text { indivíduos }\end{array}$} & \multicolumn{2}{|c|}{$\begin{array}{l}\text { Biomassa } \\
\text { estimada }\end{array}$} & \multicolumn{2}{|c|}{$\begin{array}{l}\text { Número } \\
\text { indivíduos }\end{array}$} & \multicolumn{2}{|c|}{$\begin{array}{l}\text { Biomassa } \\
\text { estimada }\end{array}$} \\
\hline & & $\mathrm{n}$ & $\%$ & gramas & $\%$ & $\mathrm{n}$ & $\%$ & gramas & $\%$ \\
\hline Cavia aperea & 349 & 2 & 8 & 698 & 1,2 & 1 & 4,54 & 349 & 0,89 \\
\hline Calomys tener & 20 & 2 & 8 & 40 & 0,06 & - & - & - & - \\
\hline Coendou prehensilis & 3360 & - & - & - & - & 2 & 9,09 & 6720 & 17,17 \\
\hline Dasypus novemcinctus & 3650 & 2 & 8 & 7300 & 12,3 & - & - & - & - \\
\hline Didelphidae n.i. & 940 & 1 & 4 & 940 & 1,6 & 1 & 4,54 & 940 & 2,4 \\
\hline Didelphis albiventris & 1250 & 1 & 4 & 1250 & 2,1 & 3 & 13,65 & 3750 & 9,58 \\
\hline Galictis cuja & 1580 & 3 & 12 & 4740 & 8 & 1 & 4,54 & 1580 & 4,04 \\
\hline Lutreolina crassicaudata & 537 & 1 & 4 & 537 & 1 & 1 & 4,54 & 537 & 1,37 \\
\hline Muridae n.i. & 127,22 & 1 & 4 & 127,22 & 0,21 & 2 & 9,09 & 254,44 & 0,65 \\
\hline Murinae n.i. & 179,33 & 1 & 4 & 179,33 & 0,3 & - & - & - & - \\
\hline Mus musculus & 15,5 & 1 & 4 & 15,5 & 0,02 & 2 & 9,09 & 31 & 0,08 \\
\hline Myocastor coypus & 4190 & 3 & 12 & 12570 & 21,2 & 3 & 13,65 & 12570 & 32,13 \\
\hline Nasua nasua & 5000 & 6 & 24 & 30000 & 50,1 & 2 & 9,09 & 10000 & 25,56 \\
\hline Rattus novergicus & 352,5 & - & - & - & - & 1 & 4,54 & 352,5 & 0,9 \\
\hline Rattus rattus & 170 & - & - & - & - & 1 & 4,54 & 170 & 0,43 \\
\hline Leporidae & 934 & 1 & 4 & 934 & 1,6 & 2 & 9,09 & 1868 & 4,77 \\
\hline Total & & 25 & 100 & 59331,10 & 99,69 & 22 & 95,45 & 39121,90 & 99,08 \\
\hline
\end{tabular}

$\mathrm{N}=$ quantidade de amostras de fezes de cada período. 
Tabela 9. Biomassa consumida estimada das espécies de mamíferos identificadas em 97 amostras de fezes de gatos errantes coletadas no Campus "Luiz de Queiroz"

\begin{tabular}{|c|c|c|c|c|c|c|c|c|c|}
\hline \multirow[b]{3}{*}{ Espécies presas } & \multirow{3}{*}{$\begin{array}{l}\text { Peso } \\
\text { médio } \\
(\mathrm{g})\end{array}$} & \multicolumn{4}{|c|}{ Inverno $(\mathrm{N}=48)$} & \multicolumn{4}{|c|}{ Verão ( $N=49)$} \\
\hline & & \multicolumn{2}{|c|}{$\begin{array}{l}\text { Número } \\
\text { indivíduos }\end{array}$} & \multicolumn{2}{|c|}{$\begin{array}{l}\text { Biomassa } \\
\text { estimada }\end{array}$} & \multicolumn{2}{|c|}{$\begin{array}{l}\text { Número } \\
\text { indivíduos }\end{array}$} & \multicolumn{2}{|c|}{$\begin{array}{l}\text { Biomassa } \\
\text { estimada }\end{array}$} \\
\hline & & $\mathrm{n}$ & $\%$ & gramas & $\%$ & $\mathrm{n}$ & $\%$ & gramas & $\%$ \\
\hline Cavia aperea & 349 & 2 & 14,29 & 698 & 6,22 & 2 & 16,67 & 698 & 6,85 \\
\hline Dasypus novemcinctus & 3650 & 1 & 7,14 & 3650 & 32,53 & - & - & - & - \\
\hline Didelphidae n.i. & 940 & 1 & 7,14 & 940 & 8,39 & 4 & 33,33 & 3760 & 36,85 \\
\hline Didelphis albiventris & 1250 & 2 & 14,29 & 2500 & 22,30 & - & - & - & - \\
\hline Galictis cuja & 1580 & 1 & 7,14 & 1580 & 14,08 & 2 & 16,67 & 3160 & 30,97 \\
\hline Lutreolina crassicaudata & 537 & 1 & 7,14 & 537 & 4,78 & 1 & 8,33 & 537 & 5,26 \\
\hline Muridae n.i. & 127,22 & 1 & 7,14 & 127,22 & 1,13 & - & - & - & - \\
\hline Murinae n.i. & 179,33 & 1 & 7,14 & 179,33 & 1,60 & 1 & 8,33 & 179,33 & 1,77 \\
\hline Olygoryzomys nigripes & 24,5 & 3 & 21,43 & 73,5 & 0,65 & - & - & - & - \\
\hline Leporidae & 934 & 1 & 7,14 & 934 & 8,32 & 2 & 16,67 & 1868 & 18,3 \\
\hline Total & & 14 & 99,99 & 11219,05 & 100 & 12 & 25 & 10202,33 & 100 \\
\hline
\end{tabular}

$\mathrm{N}=$ quantidade de amostras de fezes de cada período.

\subsubsection{Estimativa da Pressão de Predação da Fauna Silvestre}

O número de indivíduos de cães e gatos errantes encontrados na área de estudo foi considerado a população total da área do Campus. Assim, para a estimativa da pressão de predação sobre a fauna silvestre a biomassa consumida estimada foi calculada para cada indivíduo por dia e por ano e então multiplicada por 0,75. Este refere-se a três quartos do peso de um indivíduo, pois qualquer superestimação causada pela atribuição do peso de um adulto para indivíduos jovens, é compensada pela subestimação do peso de grandes indivíduos, principalmente machos (Schaller, 1972). Desta forma, o consumo de mamíferos por cães foi estimado entre 16,76 e 25,42 kg/ind/ano e para os gatos foi estimado entre 2,01e 2,95 kg/ind/ano (Tabela 10). 
Tabela 10. Pressão estimada de predação por cães e gatos sobre os mamíferos no Campus "Luiz de Queiroz"

\begin{tabular}{lcccccccc}
\hline & \multicolumn{4}{c}{ Inverno (N=26dias) } & \multicolumn{4}{c}{ Verão (N=29 dias) } \\
Espécie & $\mathrm{n}$ & $\mathrm{g} /$ ind/dia & $\mathrm{g} / \mathrm{ind} / \mathrm{ano}$ & $\mathrm{g} / \mathrm{km}^{2} / \mathrm{dia}$ & $\mathrm{n}$ & $\mathrm{g} / \mathrm{ind} / \mathrm{dia}$ & $\mathrm{g} / \mathrm{ind} / \mathrm{ano}$ & $\mathrm{g} / \mathrm{km}^{2} / \mathrm{dia}$ \\
\hline C. familiaris & 21 & 69,66 & 25425,90 & 265,34 & 21 & 45,93 & 16764,45 & 174,96 \\
F. catus & 50 & 5,53 & 2018,45 & 44,98 & 31 & 8,10 & 2956,50 & 40,90 \\
Total & $\mathbf{7 1}$ & $\mathbf{7 5 , 1 9}$ & $\mathbf{2 7 4 4 4 , 3 5}$ & $\mathbf{3 1 0 , 3 2}$ & $\mathbf{5 2}$ & $\mathbf{5 4 , 0 3}$ & $\mathbf{1 9 7 2 0 , 9 5}$ & $\mathbf{2 1 5 , 8 6}$ \\
\hline
\end{tabular}

$\mathrm{N}=$ quantidade de dias amostrados

$\mathrm{n}$ = população de cães e gatos no período de estudo 


\section{DISCUSSÃO}

A estimativa da abundância da população de cães errantes se apresentou estável para os dois períodos amostrados, inverno e verão. Vários indivíduos encontrados no inverno foram novamente registrados no verão, indicando o uso permanente da área. Porém, é possível que haja um fluxo de cães que entram e saem do Campus, eventual ou periodicamente pela inexistência de barreiras de controle. Isto poderia representar um erro no presente levantamento, mas não teve como ser detectado.

A população canina foi menor que a felina no período estudado. Esta diferença pode ocorrer em função do fator reprodutivo das duas espécies, pois os gatos em estado errante se reproduzem mais rápido que os cães (Bassetti ${ }^{2}$ ). Em adição, cães normalmente têm uma área de vida maior que os gatos (Macdonald \& Carr, 1995).

Coleman et al. (1997) constataram que a população de gatos nos Estados Unidos aumenta mais rapidamente em lugares com maior disponibilidade de alimentos. Neste estudo, a quantidade de alimentos não foi medida, porém foi observado que constantemente pessoas depositam alimentos para os gatos em vários pontos do Campus. No entanto, essa atitude não foi observada com a mesma freqüência para os cães.

Com relação ao uso do habitat, a maior abundância de cães e gatos encontrada para a área suburbana, se deve ao estreito relacionamento que os animais mantém com os humanos. A disponibilidade de alimento gerado pelos

\footnotetext{
${ }^{2}$ BASSETTI, L.A.B. Comunicação Pessoal, 2004.
} 
humanos nas áreas suburbanas é aparentemente maior que na área rural. $\mathrm{O}$ mesmo foi constatado por Churcher \& Lawton (1984) em uma vila inglesa. Alguns indivíduos foram observados constantemente próximos a estabelecimentos como lanchonetes e restaurantes, que permitem fácil acesso a alimentos. As áreas suburbanas do Campus contêm grande fluxo de pessoas que diariamente geram grande quantidade de lixo tornando-se uma grande fonte de alimento para cães e gatos errantes, semelhante à situação também descrita por Jackson (1951). Uma conscientização das pessoas que freqüentam o Campus com relação ao lixo gerado e o fornecimento de alimento para os animais poderia minimizar a frequência desses animais na área.

No Brasil, nenhum estudo sobre hábitos alimentares de cães e gatos errantes foi realizado. No entanto em outras partes do mundo algumas pesquisas afirmam que os cães domésticos causam um grande impacto nas populações de animais silvestres (Butler et al., 2004; Churcher \& Lawton 1987; Coleman \& Temple, 1989; Coleman et al., 1997; George, 1974; Nesbitt, 1975) enquanto outras consideram concluem que as predações não afetam a fauna local ou que o impacto pode diminuir quando existe alimento disponível, normalmente fornecido por humanos (Butler \& du Toit, 2002, Fitzgerald, 1988, Lowry \& McArthur, 1978). Estes diversos resultados podem estar relacionados com as condições locais como a abundância da fauna silvestre e a oferta de fontes alternativas de alimento (Boitani et al., 1995).

A análise da dieta dos cães na área de estudo, demonstrou o consumo de grande variedade de itens alimentares. Esta condição é vantajosa a cães errantes, pois permite flexibilidade em seu hábito alimentar (Langguth, 1975). A verificação de um comportamento oportunista dos cães errantes na área de estudo, coincide com os resultados obtidos em outras regiões, como na Itália (Macdonald \& Car, 1995), América do Norte (Daniels \& Bekoff, 1989; Lantis, 1980) e Ásia (Corbett, 1995). 
A presença comum de grama nas amostras fecais pode estar relacionada a aspectos nutricionais ou sanitários. Ela pode auxiliar a coesão da ingesta e a eliminação de parasitas (Fitzgerald, 1988).

Crespo (1975) pesquisou a dieta da raposa-cinza (Dusicyon gymnocercus) e da raposa-grande (D. culpaeus culpaeus) na Argentina e verificou que ambas são onívoras, utilizando uma grande variedade de itens vegetais e animais balanceados durante o ano.

Em relação aos itens de origem animal, os invertebrados foram mais freqüentes nas amostras. No entanto, a alta freqüência de Hymenoptera pode estar associada a sua maior abundância no lixo. Quanto aos vertebrados, os resultados coincidem com Butler \& du Toit (2002). Na dieta de canídeos é freqüente a presença de grande quantidade de roedores (Bueno et al., 2003; Crespo, 1975). No entanto, a presença de coatis ( $N$. nasua), foi maior do que roedores, confirmando uma atividade de caça a espécies de maior porte, comumente registrada (Boitani, 1995; Butler \& du Toit, 2002).

As informações referentes à capivara (Hydrochoerus hydrochaeris) foram excluídas na análise da biomassa consumida estimada para os cães errantes em função de seu alto peso em relação à baixa taxa de ocorrência ( $N$ =1). Há evidências no Campus de interações agonísticas entre machos adultos (conforme descrito por Ferraz et al., 2001), que podem resultar em mortalidade, podendo haver então consumo oportunístico da carcaça e não predação em si.

A dieta dos gatos também é influenciada pela disponibilidade de alimentos diversos no Campus. Os itens não alimentares estão presentes em proporção aproximada a de mamíferos. A identificação de $70 \%$ dos itens de origem animal confirma o comportamento natural de predação desta esta espécie (Warner, 1985). No entanto, a dieta pode variar de acordo com o grau de relacionamento com os humanos. Liberg (1984) comparou a dieta de gatos domésticos e gatos ferais por meio de análise das fezes coletadas em jardins e caixas de areia de gatos domésticos e fezes coletadas em fazendas abandonadas e outros lugares regularmente freqüentados por gatos ferais. A 
dieta dos gatos domésticos foi similar à dieta dos gatos ferais. No entanto, os gatos domésticos comiam mais alimento fornecido pelos donos e caçavam menos lebres. Já Fitzgerald (1988), fez a mesma comparação e verificou que, mesmo que gatos domésticos tenham acesso a áreas abertas, eles podem se alimentar exclusivamente do que é fornecido por seus donos, não apresentando nenhum problema para a fauna silvestre local.

Churcher \& Lawton (1987), Eberhard (1954) e Fitzgerald \& Karl (1979) verificaram que os mamíferos são as presas mais importantes da dieta dos gatos, seguidos de aves, o que coincide com os resultados obtidos neste estudo. Se a importância de um item na dieta acompanha sua abundância no meio (Bailey, 1993), então o item mais frequente na dieta dos gatos no inverno, está de acordo com esta afirmação, pois de acordo com Gheler-Costa et al. (2002), O. nigripes é a espécie mais abundante no Campus. Por outro lado, a identificação de G. cuja, M. musculus e Rattus novergicus em amostras de fezes permitiu o primeiro registro destas espécies para a área de estudo.

A amplitude do nicho trófico demonstrou que na dieta dos cães, os itens estão distribuídos de uma maneira equilibrada tanto no inverno quanto no verão, confirmando o uso variável dos recursos disponíveis no campus e uma dieta onívora. Scott \& Causey (1973) observaram que cães ferais garantiam sua sobrevivência obtendo grande quantidade de alimento no lixo. No entanto, diversos carnívoros silvestres também utilizam o lixo como forma alternativa de alimento (Alvarez, 1993; Van Druff et al., 1996). Este hábito pode ser vantajoso aos cães errantes em relação aos selvagens (Young \& Jackson, 1951).

Os gatos apresentaram uma amplitude de nicho maior no inverno do que no verão. Se analisarmos a biomassa consumida estimada pelos gatos, verificamos que no inverno foram consumidas 10 espécies. Já no verão esse número foi reduzido a seis, sugerindo uma maior seleção quando a disponibilidade de alimento é maior, o mesmo resultado encontrado por Karl \& Best (1982) e Fitzgerald et al. (1991). 
A análise do total dos itens alimentares de cães e gatos errantes demonstrou uma dieta onívora. Apesar da diferença de tamanho das duas espécies, a sobreposição de nicho é quase completa (aproximadamente 97\%). Isto pode ocorrer pelo fato das duas espécies se encontrarem em ambiente altamente alterado (Gheler-Costa et al., 2002), fazendo com que consumam oportunisticamente todos os recursos disponíveis.

Neste estudo, a biomassa consumida estimada para os cães foi entre 45,93 a 69,99 g/dia, demonstrando baixo consumo de mamíferos na área de estudo. Uma pesquisa realizada com coiotes (Canis latrans, 11-18kg de peso) (Gier, 1975), estimou um consumo de $600 \mathrm{~g}$ de carne por dia por dia. Se compararmos com o lobo (Canis lupus), espécie com peso semelhante ao de alguns cães (25-35kg de peso), verificamos que a biomassa média consumida por indivíduo pode chegar a cerca de $3 \mathrm{~kg}$ de carne por dia (Ciucci, et al. 1996) o que é bem superior aos resultados do presente estudo.

Apesar da quantidade da biomassa consumida estimada para os cães ser inferior aos valores encontrados na literatura, a densidade de mamíferos silvestres no Campus é baixa (Gheler-Costa et al., 2002), o que pode estar relacionado a eles que em ambientes alterados, mesmo um consumo relativamente baixo de presas silvestres, pode ser responsável por seu declínio populacional.

Quanto aos resultados da biomassa consumida estimada para os gatos, verificou-se que estes animais consomem entre 5,53 a 8,10 g/ind/dia. 0 número de presas consumidas pelos gatos não foi elevado se comparado com os dados obtidos por George (1974) e Bradt (1949), resultando uma média de 26 e 92 presas/mês respectivamente.

Churcher \& Lawton (1987) pesquisaram a predação por gatos domésticos numa vila inglesa com uma quantidade de gatos que variou entre 69 e 71 indivíduos, e notaram que conforme a densidade de gatos aumentava a quantidade de presas capturadas por gato diminuía. Assim, a competição diminui as chances de captura, aumentando, no entanto, a predação. 
Cães e gatos errantes são um velho problema com que muitos países estão lidando com diferentes graus de sucesso. Um raro exemplo de relativo sucesso é a Grã-Betanha, onde apesar de haver aproximadamente sete milhões de cachorros, é raro encontrar um indivíduo errante devido à conscientização da população sobre as responsabilidades que envolvem ter um animal de estimação (Boitani et al., 1995).

Vários fatores podem influenciar na distribuição e abundância da fauna silvestre, de forma especial em ambientes antrópicos. As espécies silvestres estão sujeitas à flutuações sazonais na disponibilidade de alimento, e alterações ambientais (Emmons, 1987), podendo ainda sofrer predação ou competição de cães e gatos (Coleman et al., 1997). Tais fatores devem ser considerados para sua conservação. 


\section{CONCLUSÕES}

\subsection{Considerações Finais}

A quantidade de cães e gatos errantes no Campus "Luiz de Queiroz" é grande e o Campus não está estruturado para a manutenção destas espécies que podem estar associadas a zoonoses e epizootias, além de predarem espécies silvestres. A quantidade de animais silvestres predados pode ser relativamente baixa se comparada a ambientes naturais. No entanto ela pode comprometer a biodiversidade local que já apresenta baixa densidade. Desta forma, algumas providências poderiam ser tomadas para minimizar os riscos que esses animais apresentam.

Uma campanha de educação para os freqüentadores (visitantes, funcionários, professores e estudantes) do Campus poderia ser programada pela Prefeitura do Campus com o auxílio de voluntários.

Inicialmente, os freqüentadores devem tomar conhecimento da biodiversidade existente no Campus para sua valorização. Juntamente com esta campanha, poderia ser ressaltada a necessidade de manejo adequado do lixo produzido pelos freqüentadores, reforçando a importância do uso das lixeiras altas, fora do alcance de cães e gatos e espécies silvestres. Além disso, a proibição do fornecimento de alimentos para cães e gatos errantes deve. Em adição, as informações sobre as principais zoonoses transmitidas por cães e gato poderiam ser enfatizadas.

Para o prosseguimento da campanha de o controle da população de cães e gatos errantes, poderiam ser distribuídos cartazes com o aviso da proibição de abandono de animais no Campus nos locais onde freqüentemente 
encontramos novos animais abandonados, e também a remoção de alimentos deixados por frequentadores nesses locais. Numa etapa posterior, deveria-se partir para a retirada de cães e gatos errantes pelo serviço municipal de controle de zoonoses ou pela própria Prefeitura do Campus. Para isto, sociedades de proteção animal poderiam ser contactadas para auxiliar na destinação de animais a possíveis interessados. Por fim, animais de estimação mantidos por funcionários residentes deveriam ser identificados com coleira e/ou micro-ship, devendo permanecer no perímetro residencial.

Atualmente, visitantes são proibidos de trazerem cães, mesmo presos a coleiras, em passeios pelo Campus. No entanto, isto não tem impedido que pessoas abandonem animais na área, o que apresenta, isto sim, o principal problema em relação a tais espécies, devendo ser coibido e fiscalizado. Animais de estimação poderiam voltar a freqüentar o Campus, a exemplo do que se faz mesmo em shopping-centers de grandes centros urbanos. Para isto, seria necessário apenas que fossem mantidos na coleira, junto a seus donos e que estes procedessem à coleta e transporte de suas fezes em sacos plásticos, a exemplo do que já ocorre em diversas cidades do mundo. Desta forma, seriam retirados os cães e gatos errantes do Campus, permanecendo apenas animais de estimação devidamente cuidados, cujo dano à biodiversidade local e à saúde pública é irrelevante. 


\subsection{CONCLUSÕES}

1. A quantidade de cães e gatos errantes no Campus "Luiz de Queiroz" é grande, aumentando os riscos de transmissão de doenças para animais silvestres ou domésticos e para os humanos.

2. As predações de animais silvestres comprometem as populações existentes no Campus, visto que já se apresentam em baixas densidades.

3. Cães e gatos errantes no Campus deverão ser manejados.

4. Faz-se necessário a aplicação de campanhas educativas para os freqüentadores do Campus, sobre o manejo de lixo gerado, o fornecimento de alimento para cães e gatos errantes e o abandono de cães e gatos no Campus.

5. Adoção destas campanhas para o calendário anual da ESALQ. 


\section{REFERÊNCIAS BIBLIOGRÁFICAS}

ACKERMAN, B.B.; LINDZEY, F.G.; HEMKER, T.P. Cougar food habits in southern Utah. Journal of Wildlife Management, v.48, n.1, p.147-155, June 1984.

ALVAREZ, K. Twilight of the panthers: biology, bureaucracy and failure in an endangered species program. Savasota: Myakka River Publishing, 1993. 501p.

BAILEY, T.N. The African leopard: ecology and behavior of a solitary felid. New York: Columbia University Press, 1993. 429p.

BARBIN, H.S. Estudo das transformações na conformação dos maciços arbóreo/arbustivos do Parque da Escola Superior de Agricultura "Luiz de Queiroz" Universidade de São Paulo, através de fotografias aéreas verticais e levantamentos florísticos de épocas distintas. Piracicaba, 1999. 94p. Dissertação (Mestrado) Escola Superior de Agricultura "Luiz de Queiroz", Universidade de São Paulo.

BECK, A.M. The ecology of feral and free roving dogs in Baltimore. In: FOX, M.W. (Ed.). The wild canids: their systematics, behavioral ecology end evolution. Malabar: Robert E. Krieger Publishing, 1975. p.380-390.

BISBAL, F.J. Food habits of some neotropical carnivores in Venezuela (Mammalia, Carnivora). Mammalia, v.50, n.3, p.329-339, 1986.

BOITANI, L.; FRANCISCI, F.; CIUCCI, P.; ANDREOLI, G. Population biology and ecology of feral dogs in central Italy. In: SERPELL, J. (Ed.). The domestic dog: its evolution, behavior and interactions with people. Cambridge: Cambridge University Press, 1995. p.217-244. 
BRADSHAW, J.W.S.; NOTT, H.M.R. Social and communication behaviour of companion dogs. In: SERPELL, J. (Ed.). The domestic dog: its evolution, behavior and interactions with people. Cambridge: Cambridge University Press, 1995. p.115-130.

BRADSHAW, J.W.S.; GOODWIN, D.; LEGRAND-DEFRETIN, V.; NOTT, H.M.R. Food selection by domestic cat, an obligate carnivore. Compartive Biochemistry and Physiology, Part A: Physiology, v.114A, n.3, p.205-209, July 1996.

BRADT, G.W. Farm cat as predator. Michigan Conservation, v.18, n.4, p.23-25, 1949.

BUENO, A.A.; BELENTANI, S.C.S.; MOTTA JUNIOR, J.C. Feeding ecology of the maned wolf, Chrysocyon brachyurus (Illiger, 1815) (Mammalia: Canidae), in the Ecological Station of Itirapina, São Paulo State, Brazil. Biota Neotropica, v.2, n.2, p.1-9, Jan 2003.

BUTLER, J.R.A.; DU TOIT, J.T. Diet of free-ranging domestic dogs (Canis familiaris) in rural Zimbabwe: implications for wild scavengers on the periphery of wildlife reserves. Animal Conservation, v.5, p.29-37, 2002.

BUTLER, J.R.A.; DU TOIT, J.T.; BINGHAM, J. Free-ranging domestic dogs (Canis familiaris) as predators and prey in rural Zimbabwe: threats of competition and disease to large wild carnivores. Biological Conservation, v.115, p.369-378, 2004.

CAUSEY, M.K.; CUDE, C.A. Feral dog and white-tailed deer interactions in Alabama. Journal of Wildlife Management, v.44, p.481-484, 1980.

CAVALCANTI, S.M.C. Manejo e controle de danos causados por espécies da fauna. In: CULLEN JUNIOR, L.; RUDRAN, R.; VALLADARES-PÁDUA, C. (Org.). Métodos de estudos em biologia da conservação e manejo de vida silvestre. Curitiba: UFPR/Fundação O Boticário de Proteção à Natureza, 2003. p.203-242.

Centro de Controle de Zoonoses, São Paulo. http://www.prodam.sp.gov.br/sms/zoonoses/ (17 set 2002).

CHURCHER, P.B.; LAWTON, J.H. Predation by domestic cats in an English village. Journal of Zoology, v.212, p. 439-455, 1987. 
CIUCCI, P.; BOITANI, L.; PELLICCIONI, E.R.; ROCCO, M.; GUY, I. A comparison of scat-analysis methods to assess the diet of the wolf Canis lupus. Wildlife Biology, v.2, n.1, p.37-48, 1996.

CLUTTON-BROCK, J. Dog. In: MASON, I.L. (Ed.). Evolution of domesticated animals. New York: Longman, 1984. p.198-211.

CLUTTON-BROCK, J. The carnivore remains excavated at fell's cave in 1970. In: HYSLOP, J. (Ed). Travels and archaeology in south Chile by Junius B. Bird. lowa City: University of lowa Press, 1988. p.188-295.

CLUTTON-BROCK, J. Origins of the dog: domestication and early history. In: SERPELL, J. (Ed.). The domestic dog: its evolution, behavior and interactions with people. Cambridge: Cambridge University Press, 1995. p.7-20.

COELHO, L.M.P.S.; DINI, C.Y.; MILMAN, M.H.S.A.; OLIVEIRA, S.M. Toxocara spp. eggs in public squares of Sorocaba, São Paulo State, Brazil. Revista do Instituto de Medicina Tropical de São Paulo, v.43, n.4, p.189-191, 2001.

COLEMAN, J.S.; TEMPLE, S.A. Effects of free-ranging cats on wildlife: a progress report. Proceedings of. Eastern Wildlife Damage Control Conference, v.4, p.912, 1989.

COLEMAN, J.S.; TEMPLE, S.A.; CRAVEN, S.R. Cats and Wildlife: A conservation dilemma. Madison: University of Wisconsin, 1997. http://wildlife.wisc.edu/extension/catfly3.htm. (24 set 2002).

CORBETT, L.K. The dingo in Australia and Asia. Sydney: University of New South Wales Press, 1995. 1v.

CORREA, W.M.; CORREA, C.N.M. Enfermidades infecciosas dos mamíferos domésticos. 2.ed. São Paulo: Medsi, 1992. 1v.

CRAWSHAW JUNIOR, P.G. Recomendações para um modelo de pesquisa sobre Felídeos Neotropicais. In: VALLADARES-PÁDUA, C.; BODMER, R.E.; CULLEN JUNIOR, L. (Ed.). Manejo e conservação de vida silvestre no Brasil. Brasília: CNPq /MCT, Tefé: Sociedade Civil Mamirauá, 1997. p.70-94. 
CRESPO, J.A. Ecology of pampus gray fox and the large fox (Culpeo). In: FOX, M.W. (Ed.). The wild canids: their systematics, behavioral ecology end evolution. Malabar: Robert E. Krieger Publishing, 1975. p.192-206.

CULLEN JUNIOR, L. Hunting and biodiversity in Atlantic forest fragments, São Paulo, Brazil. Florida, 1999. 134p. Tese (Mestrado) - University of Florida.

DANIELS, T.J.; BEKOFF, M. Spatial and temporal resource use by feral and abandoned dogs. Ethology, v.81, p.300-312, 1989.

EBERHARD, T. Food habits of Pennsylvania house cats. Journal of Wildlife Management, v.18, p. 284-286, 1954.

EMMONS, L.H. Geographic variation in densities and diversities of nonflying mammals in Amazonia. Biotropica, v.16, p.210-222, 1984.

EMMONS, L.H. Comparative feeding ecology of felids in a neotropical rainforest.

Behavior Ecology and Sociobiology, v.20, p.271-283, 1987.

EMMONS, L.H. Neotropical rainforest mammals: a field guide. 2.ed. Chicago: University of Chicago Press, 1997. 307p.

ERRINGTON, P.I. Notes on food habits of southern Wisconsin house cats. Journal of Mammalogy, v.17, p.64-65, 1936.

FERRAZ, K.P.M.B.; SANTOS FILHO, R.M.F.; PIFFER, T.R.O.; VERDADE, L.M. Biologia e manejo da capivara: do controle de danos ao máximo rendimentos sustentável. In: MATTOS, W.R.S. et al. (Ed.). A produção animal na visão dos brasileiros. Piracicaba: FEALQ, 2001. p.580-588.

FITZGERALD, B.M. Diet of domestic cats and their impact on prey populations. In: TURNER, D.C.; BATESON, P. (Ed.). The domestic cat: the biology of its behaviour. Cambridge: Cambridge University Press, 1988. p.123-146.

FITZGERALD, B.M.; KARL, B.J. Food of feral house cats (Felis catus L.) in forests of the Orongorongo Valley, Wellington. New Zealand Journal of Zoology, v.6, p.107126, 1979. 
FITZGERALD, B.M.; KARL, B.J.; VEITCH, C.R. The diet of feral cats (Felis catus) on Raoul Island, Kermadec group. New Zealand Journal of Ecology, v.15, p.123129, 1991.

FITZWATER, W.D. House cats (feral). In: HYGNSTRON, S.E.; TIMM, R.M.; LARSON, G.E. (Ed.). Prevention and control of wildlife damage. 3.ed. Lincoln: University of Nebraska, 1994. p.C45-C49.

FONSECA, G.A.B.; HERRMANN, G.; LEITE, Y.L.R.; MITTERMEIER, R.A.; RYLANDS, A.B.; PATTON, J.L. Lista anotada dos mamíferos do Brasil. Washington: Conservation International, Fundação Biodiversitas, 1996. (Occasional Paper, 4). FRENKEL, J.K. Toxoplasmose. In: VERONESI, R.; FOCCACIA, R. (Ed.). Tratado de infectologia. 2.ed. São Paulo: Ateneu, 1997. cap.99. p.1290-1305.

GARLA, R.C.; SETZ, E.Z.; GOBBI, N. Jaguar (Panthera onca) food habits in Atlantic rain forest of southeastern Brazil. Biotropica, v.33, n.4, p.691-696, 2001.

GEORGE, W.G. Domestic cat as predators and factors in winter shortages of raptor prey. Wilson Bulletin, v.86, p.384-396, 1974.

GHELER-COSTA, C.; VERDADE, L.M.; ALMEIDA, A.F. de. Mamíferos não-voadores do campus "Luiz de Queiroz" da Universidade de São Paulo, Piracicaba, Brasil. Revista Brasileira de Zoologia, v.19, n.2, p.203-214, 2002. (suplemento).

GIER, H.T. Ecology and social behavior of the coyote. In: FOX, M.W. (Ed.). The wild canids: their systematics, behavioral ecology end evolution. Malabar: Robert E. Krieger Publishing, 1975. p.380-390.

GREEN, G.A.; WITMER, G.W.; DE CALESTA, D.S. NaOH Preparation of mammalian predator scats for dietary analysis. Journal of Mammalogy, v.67, n.4, p.742, 1986.

GREEN, J.S.; GIPSON, P.S. Feral dogs. In: HYGNSTRON, S.E.; TIMM, R.M.; LARSON, G.E. (Ed.). Prevention and control of wildlife damage. 3.ed. Lincoln: University of Nebraska, 1994. p.C-77-C-81.

HAUSMAN, L.A. Strictutal characteristics of the hair of mammals. American Naturalist, v.54, n.635, p.496-523, 1920. 
HENSCHEL, J.R.; SKINNER, J.D. The diet of the spotted hyena (Crocuta crocuta) in Kruger National Park. African Journal of Ecology, v.28, p.69-82, 1990.

INSTITUTO BRASILEIRO DE GEOGRAFIA E ESTATÍSTICA. Manual técnico da vegetação brasileira. Rio de Janeiro, 1992. n.1.

JACKSON, W.B. Food habits of Baltimore, Maryland, cats in relation to rat populations. Journal of Mammalogy, v.32, n.4, p.458-461, 1951.

KOONZ, C.H.; STRANDINE, E.J. A rapid and simplified method for revealing the surface pattern of hair. Transactions of the American Microscopy Society, v.64, n.1, p.63-64, 1945.

KREBS, C.J. Ecological methodology. New York: Harper \& Row, 1989. 654 p.

KREBS, C.J. Ecological methodology. 2.ed. New York: Harper \& Row, 1999. 581 p.

LANGGUTH, A. Ecology and evolution in the South American canids. In: FOX, M.W. (Ed.). The wild canids: their systematics, behavioral ecology end evolution. Malabar: Robert E. Krieger Publishing, 1975. p.192-206.

LANTIS, M. Changes in the Alaskan Eskimo relation of man to dos and their effect on two human diseases. Artic Anthropology, v.17, p.17-24, 1980.

LEVINS, R. Evolution in changing environments: some theoretical explorations. Princeton: Princeton University Press, 1968. 1v.

LIBERG, O. Food habits and prey impact by feral and house-based domestic cats in a rural area in southern Sweden. Journal of Mammalogy, v.65, p.424-432, 1984.

LITVAITIS, J.A.; TITUS, K.; ANDERSON, E.M. Measuring vertebrate use of terrestrial habitats and foods. In: BOOKHOUT, T.A. (Ed.). Research and management techniques for wildlife and habitats. 5.ed. Bethesda: Wildlife Society, 1996. p.254-274.

LOCKWOOD, R. The ethology and epidemiology of canine agression. In: SERPELL, J. (Ed.). The domestic dog: its evolution, behavior and interactions with people. Cambridge: Cambridge University Press, 1995. p.131-138.

LOVERIDGE, A.J.; MACDONALD, D.W. Niche separation in sympatric jackals (Canis mesomelas and Canis adustus). Journal of Zoology, v.259, p.143-153, 2003. 
LOWRY, D.A.; MCARTHUR, K.L. Domestic dogs as predators on deer. Wildlife Society Bulletin, v.6, n.1, p.38-39, 1978.

MACDONALD, D.W.; CARR, G.M. Variation in dog society: between resource dispersion and social flux. In: SERPELL, J. (Ed.). The domestic dog: its evolution, behavior and interactions with people. Cambridge: Cambridge University Press, 1995. p.199-216.

MARTIN, P.; BATESON, P. Behavioural development in cat. In:TURNER, D.C.; BATESON, P. (Ed.). The domestic cat: the biology of its behaviour. 2ed. Cambridge: Cambridge University Press, 1988. p.9-22.

MASCOLLI, R.; PINHEIRO, S.R.; VASCONCELLOS, S.A.; FERREIRA, F.; MORAIS, Z.M.; PINTO, C.O.; SUCUPIRA, M.C.A.; DIAS, R.A.; MIRADIA, F.; CORTEZ, A.; COSTA, S.S.; TABATA, R.; MARCONDES, A.G. Inquérito sorológico para leptospirose em cães do Município de Santana de Parnaíba, São Paulo, utilizando a campanha de vacinação anti-rábica do ano de 1999. Arquivos do Instituto Biológico, v.69, n.2, p.25-32, 2002.

MILLS, M.G.C. Methodological advances in capture, census, and food habits studies of large African carnivores. In: GITTLEMAN, J.L. (Ed.). Carnivore behavior, ecology, and evolution. New York: Cornell University, 1996. v.2, p.223-242.

MOREY, D.F. The early evolution of the domestic dog. American Scientist, v.82, p.336-347, July-Aug, 1994.

MOTTA JUNIOR, J.C.; TALAMONI, S.A.; LOMBARDI, J.A., SIMOKO,AKI, K. Diet of the maned wolf, Chrysocyon brachyurus, in central Brazil. Journal of Zoology, v.240, p.277-284, 1996.

NESBITT, W.H. Ecology of a feral dog pack on a wildlife refuge. In: FOX, M.W. (Ed.).

The wild canids: their systematics, behavioral ecology end evolution. Malabar: Robert E. Krieger Publishing, 1975. p. 391-395.

OLIVEIRA, T.G. de. Neotropical cats: ecology and conservation. São Luís: EDUFMA, 1994. $220 \mathrm{p}$.

OLIVEIRA, T.G. de; CASSARO, K. Guia de identificação dos felinos brasileiros. 2.ed. São Paulo: Sociedade de Zoológicos do Brasil, 1999. 60 p. 
PITMAN, M.R.P.L.; OLIVEIRA, T.G. de; PAULA, R.C. de; INDRUSIAK, C. Manual de identificação, prevenção e controle de predação por carnívoros. Brasília: Edições IBAMA, 2002. 83 p.

QUADROS, J. Identificação microscópica de pêlos de mamíferos brasileiros e sua aplicação no estudo da dieta de carnívoros. Curitiba, 2002. 127 p. Tese (Doutorado) - Universidade Federal do Paraná.

RATTI, J.T.; GARTON, E.O. Research and experimental design. In: BOOKHOUT, T.A. (Ed.). Research and management techniques for wildlife and habitats. 5.ed. Bethesda: Wildlife Society, 1996. p. 1-23.

REYNOLDS, J.C.; AEBISCHER, N.J. Comparison and quantification of carnivore diet by faecal analysis: a critique, with recommendations, based on a study of the fox, Vulpes vulpes. Mammal Review, v.21, n.3, p.97-122, 1991.

ROBINSON, R. Cat. In: MASON, I.L. (Ed.). Evolution of domesticated animals. New York: Longman, 1984. p. 217-225.

RUDRAN, R.; KUNZ, T.H.; SOUTHWELL, C.; JARMAN, P.; SMITH, A.P. Observational techniques for nonvolant mammals. In: WILSON, D.E.; COLE, F.R.; NICHOLS, J.D., RUDRAN, R.; FOSTER, M.S. (Ed.). Measuring and monitoring biological diversity: standard methods for mammals. Washington, London: Smithsonian Institution, 1996. p.81-103.

RUPPERT, E.E.; BARNER, R.D. Zoologia dos invertebrados. 6.ed. Tradução: P.M. Oliveira. São Paulo: Roca, 1996. 1073p.

SCHALLER, G.B. The Serengeti lion: a study of predator-prey relations. Chicago: University of Chicago Press, 1972. 480p.

SCOTT, M.D.; CAUSEY, K. Ecology of feral dogs in Alabama. Journal of Wildlife Management, v.37, n.3, p.253-265, 1973.

SERPELL, J. (Ed.). The domestic dog: its evolution, behaviour and interactions with people. Cambridge: Cambridge University Press, 1995. 268 p. 
SERPELL, J. Domestication and history of domestic cat. In: TURNER, D.C.;

BATERSON, P. (Ed.). The domestic cat: the biology of its behaviour. 2.ed. Cambridge: Cambridge University Press, 2000. p.179.

SETZER, J. Contribuição para o estudo do clima do estado de São Paulo. São Paulo: D.E.R., 1946. 237p.

SPAROVEK, G. Avaliação das terras do Campus "Luiz de Queiroz": aspectos físicos, capacidade de uso, uso da terra, adequação de uso e aptidão. Piracicaba: ESALQ, Departamento de Solos, 1993. 40p.

SUTHERLAND, W.J. Ecological census techniques: a handbook. Cambridge: Cambridge University Press, 1996. 336 p.

TEERINK, B.J. Hair of west-European mammals: atlas and identification key. Cambridge: Cambridge University Press, 1991. 232 p.

VAN DRUFF, L.N.; BOLEN, E.G.; SAN JULIAN, G.J. Management of urban wildlife. In: BOOKHOUT, T.A. (Ed.). Research and management techniques for wildlife and habitats. Bethesda: The Wildlife Society, 1996. p.507-530.

VELOSO, H.D.; RANGEL FILHO, A.L.R.; LIMA, J.C.A. Classificação da vegetação brasileira, adaptada a um sistema universal. Rio de Janeiro: IBGE, Departamento de Recursos Naturais e Estudos Ambientais, 1991. 124 p.

WARNER, R.E. Demography and movements of free-ranging domestic cats in rural Illinois. Journal of Wildlife Management, v.49, n.2, p.340-346, 985.

WILLIAMS, C.S. A simple method for sectioning mammalian hairs for identification purpose. Journal of Mammalogy, v.15, n.3, p.251-252, 1938.

YOUNG, S.P.; JACKSON, H.H.T. The clever coyote. Harrisburg: The Stackpole; Washington: Wildlife Management Institution, 1951. 411p.

ZAR, J.H. Biostatistical analysis. Prentice Hall: Upper Saddle River, 1999. 663 p. 